\title{
A Review of Thermal Spray Metallization of Polymer-Based Structures
}

\author{
R. Gonzalez, H. Ashrafizadeh, A. Lopera, P. Mertiny, and A. McDonald
}

(Submitted September 23, 2015; in revised form April 8, 2016)

\begin{abstract}
A literature review on the thermal spray deposition of metals onto polymer-based structures is presented. The deposition of metals onto polymer-based structures has been developed to enhance the thermal and electrical properties of the resulting metal-polymer material system. First, the description of the thermal spray metallization processes and technologies for polymer-based materials are outlined. Then, polymer surface preparation methods and the deposition of metal bond-coats are explored. Moreover, the thermal spray process parameters that affect the properties of metal deposits on polymers are described, followed by studies on the temperature distribution within the polymer substrate during the thermal spray process. The objective of this review is devoted to testing and potential applications of thermal-sprayed metal coatings deposited onto polymer-based substrates. This review aims to summarize the state-of-the-art contributions to research on the thermal spray metallization of polymer-based materials, which has gained recent attention for potential and novel applications.
\end{abstract}

Keywords electrical conductivity, metallization, polymers, thermal conductivity, thermal spraying

\section{Introduction}

Thermal spraying is a material deposition process whereby a heat source is used to increase the temperature of feedstock particles that are accelerated in a fluid stream through a spray nozzle or torch, for consolidation upon impact on a substrate. The thermal spray deposition process is characterized by heat, mass, and momentum transfer phenomena (Ref 1-3). These phenomena are functions of the thermal spray process parameters (Ref 2) and affect the properties and structure of the resulting thermal-sprayed coatings (Ref 1). Thermal energy is transferred from the thermal spray gas, flame, or plasma to the substrate by gas convection and the impingement of solid or molten particles (Ref 4). The kinetic energy of the impacting particle is used to overcome surface tension energy, deform the particles, and/or is converted to heat due to viscous dissipation or adiabatic shear instabilities during flattening to form a splat (Ref 5-7). As a result of the thermal spray deposition onto the substrate, a lamellar structure of splats develops into a coating layer, which exhibits different physical properties from those of the coating bulk material (Ref 1 ). These differences in properties can be the result of phase changes during the deposition process, residual stresses in the solidified splats, and the presence of porosities and other microstructural

R. Gonzalez, H. Ashrafizadeh, A. Lopera, P. Mertiny, and A. McDonald, Department of Mechanical Engineering, University of Alberta, Edmonton, AB T6G 1H9, Canada. Contact e-mail: andre.mcdonald@ualberta.ca. defects within the coating (Ref 8). Thermal spray deposition has been performed using different particle-substrate material systems, including metal particle and polymer-based substrates (Ref 2, 4, 9-12). The thermal spray deposition efficiency is determined as the ratio between the weight of the deposited material and feedstock particles sprayed in a given time (Ref 13,14$)$.

Thermal spray deposition of metal particles onto polymer-based structures has gained increasing attention through studies on the metallization of fiber-reinforced polymer composite (FRPC) (Ref 15-20), polymer matrix composite (PMC) (Ref 21, 22), and neat polymer substrates (Ref 23-28). Polymer-based materials, such as PMC structures, can provide enhanced mechanical properties (i.e., high specific strength and high specific stiffness) with respect to single-phase (i.e., metallic) structures. Moreover, surface coating technology has been recognized as a method to improve the service life and functional performance of advanced engineering structures (Ref 9, 29, 30). Thus, potential structural and operational advantages may be achieved through the application of thermalsprayed metal coatings to polymer-based substrates. Even though polymer-based materials can have high mechanical strength and corrosion resistance (Ref 19, 31), low operational temperatures (Ref 19), low electrical conductivity, and potential flammability (Ref 32,33) may limit their application in regulated industries. However, flammability requirements for polymer-based structures can be different depending on the specific sector regulations (e.g., aerospace, marine, and rail industry sectors) (Ref 32 ). Considering the potential advantages in practical application, the deposition of metal particles onto polymerbased substrates has been investigated to improve the thermal and electrical properties of the polymer system (Ref 17, 22, 30, 34, 35), which can allow a wider adoption of polymer-based materials in engineering applications. Even though alternative surface metal deposition 
techniques, such as physical vapor deposition (PVD) (Ref 36,37 ), chemical vapor deposition (CVD) (Ref 38), and plasma-enhanced CVD (PECVD) (Ref 39), may be applied to polymer-based structures, these techniques are relatively expensive to use (Ref 40) and not suitable to fabricate thick metallic coatings (over $100 \mu \mathrm{m}$ ) at high deposition rates $(\operatorname{Ref} 29,41)$, which is feasible by thermal spray metallization. On the other hand, thermal-sprayed metal coatings can be engineered to provide friction coefficient adaptation, dimensional control, dimensional restoration, and enhanced electromagnetic and thermal properties to functionalize polymer-based substrates in service (Ref $2,8,19,30)$. The thermal spray process also allows the deposition of coatings onto various substrate geometries and the ability to recoat damaged coatings (Ref 4). However, thermal degradation of the polymerbased substrate and formation of char may occur, which depends on the temperature of the metal particles and high-temperature gases during thermal spray deposition (Ref 42). Research on the thermal-physical behavior of metallized polymer materials can expand the scope and applications of several polymer-based materials, including structural PMC components.

The objective of this article is to present a review of the current knowledge of the thermal spray deposition of metals onto polymer-based substrates (e.g., neat polymers, and PMC) and the potential applications of the metallized polymer-based structures. In addition, the concepts associated with the thermal spray coating deposition onto polymer-based substrates, including, surface preparation, temperature distribution, and evaluation and characterization of metal coatings will be discussed in the context of specific applications where using thermal spray technology may be of benefit. The subject matter and discussion are restricted to the thermal spray deposition of pure metals or metal alloys onto polymer-based substrates.

\section{Process Description and Technologies}

\subsection{Thermal Spray Metallization of Polymer-Based Structures}

Thermal spray metallization of polymer-based structures is defined as the application of thermal spray processes to deposit metals onto a polymer substrate. Thermal spray deposition can be accomplished by embedment or adhesion of metal particles onto the polymer-based substrate in the form of deformed splats, as illustrated in Fig. 1 (Ref 43). The deposition of the metal splats is affected by the velocity and temperature of the impacting particles, the roughness and temperature of the substrate surface, and the relative angle between the particle trajectory and the substrate (Ref 4,8$)$, among others. The deposited metal particles may embed into relatively softer polymer substrates, such as nylon, polyurethane (PU), and polyethylene (PE) (Ref 23, 44, 45). Alternatively, the particles may deform and interlock upon contact with the polymer substrate surface, as shown in previous studies involving basalt and glass fiber-reinforced epoxy thermosets (Ref 17, 18) and pre-treated thermoplastic PU (Ref 20). Table 1 shows an overview of the thermal spray processes and material systems reported on the metallization of polymer-based structures to date.

The microstructure and physical properties of metal coatings deposited onto polymer-based substrates are influenced, in part, by the kinetic energy of the sprayed particles and the temperature of the fluid stream in which the deposited particles were entrained, which is usually a gas (Ref 2,9). Current thermal spray metallization processes of polymer-based substrates can be classified into four categories according to the primary energy source used for particle acceleration and heating (Ref 2, 3, 46). They are (i) cold spraying, which consists of kinetic-based

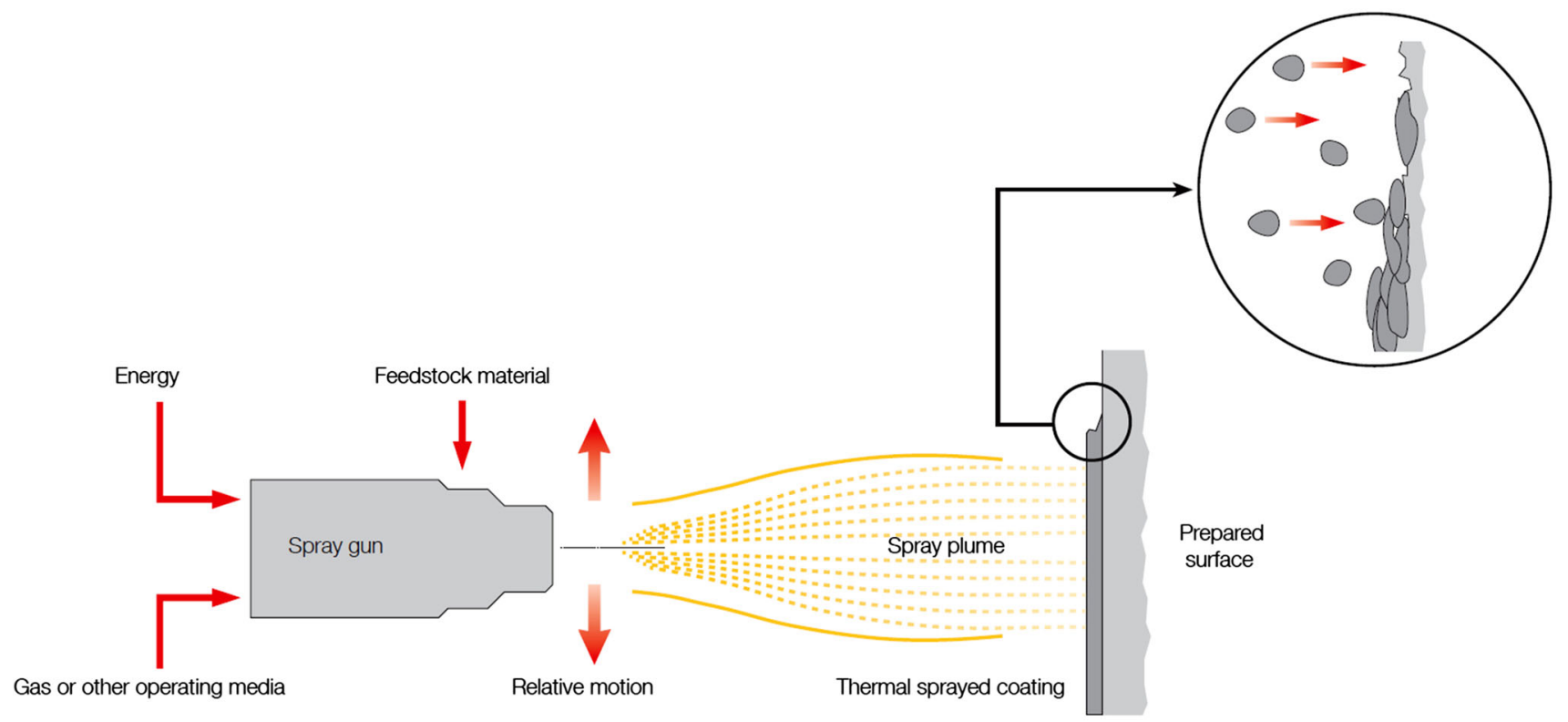

Fig. 1 Schematic of the thermal spray process (Ref 43) 


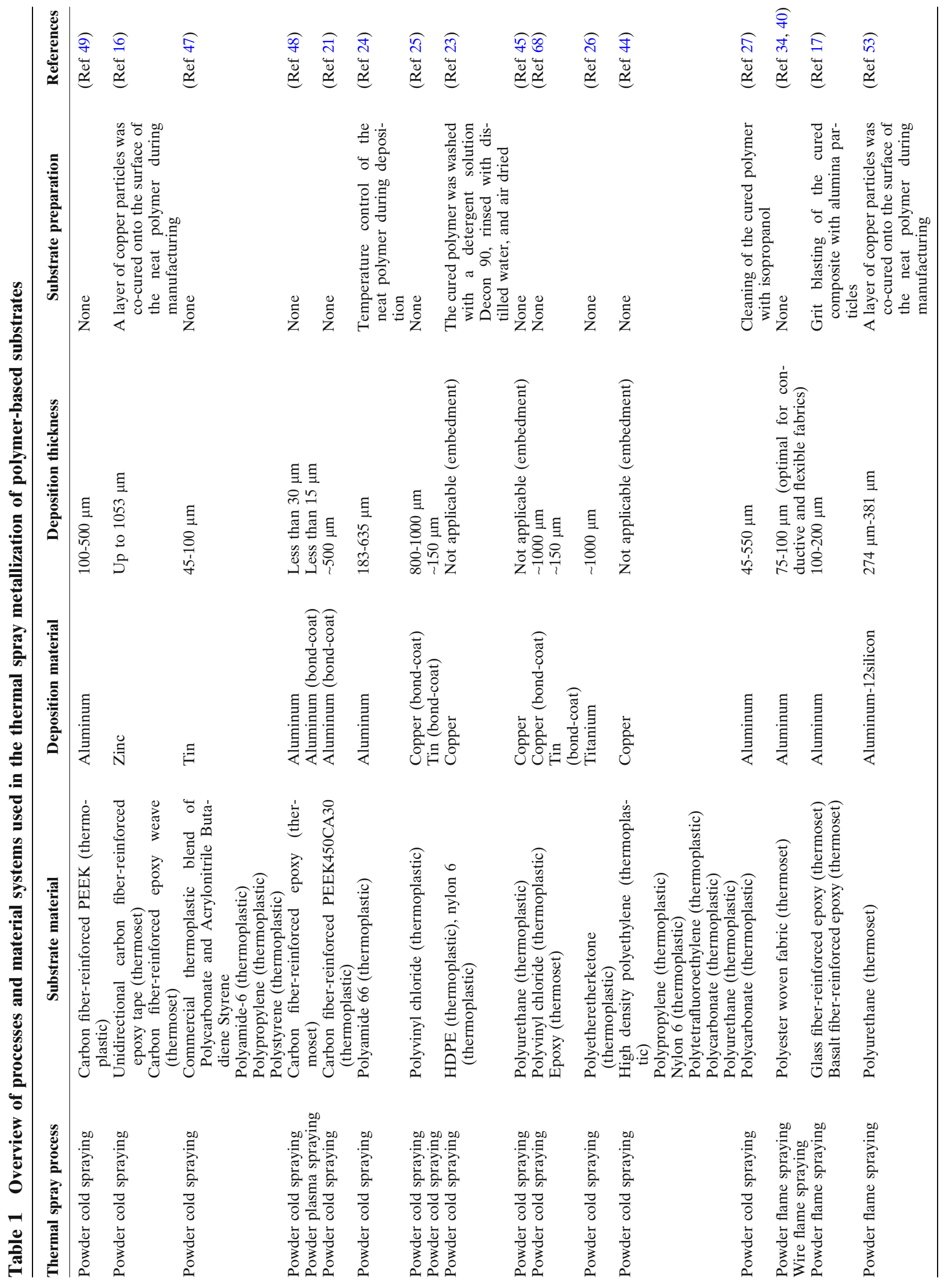




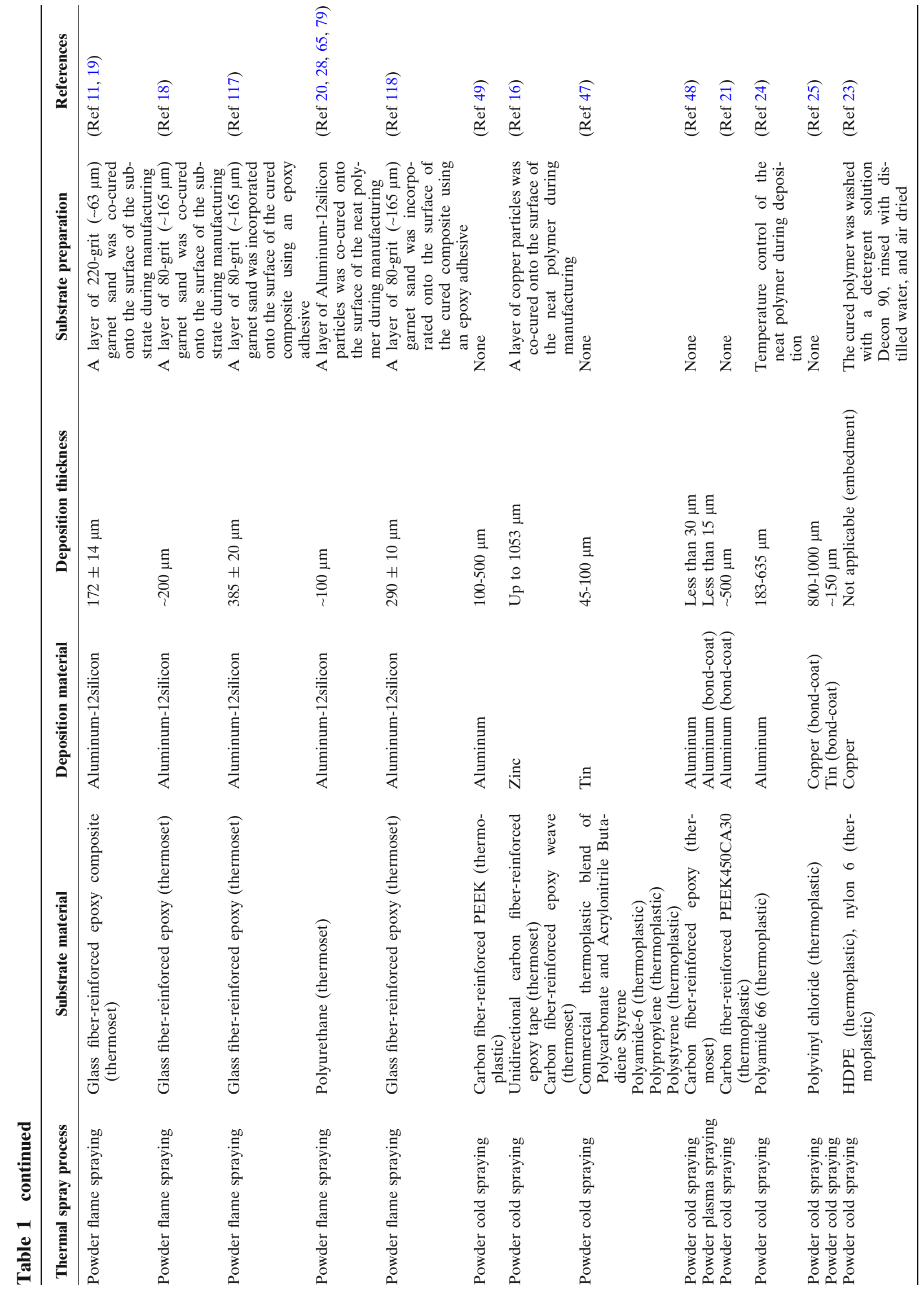




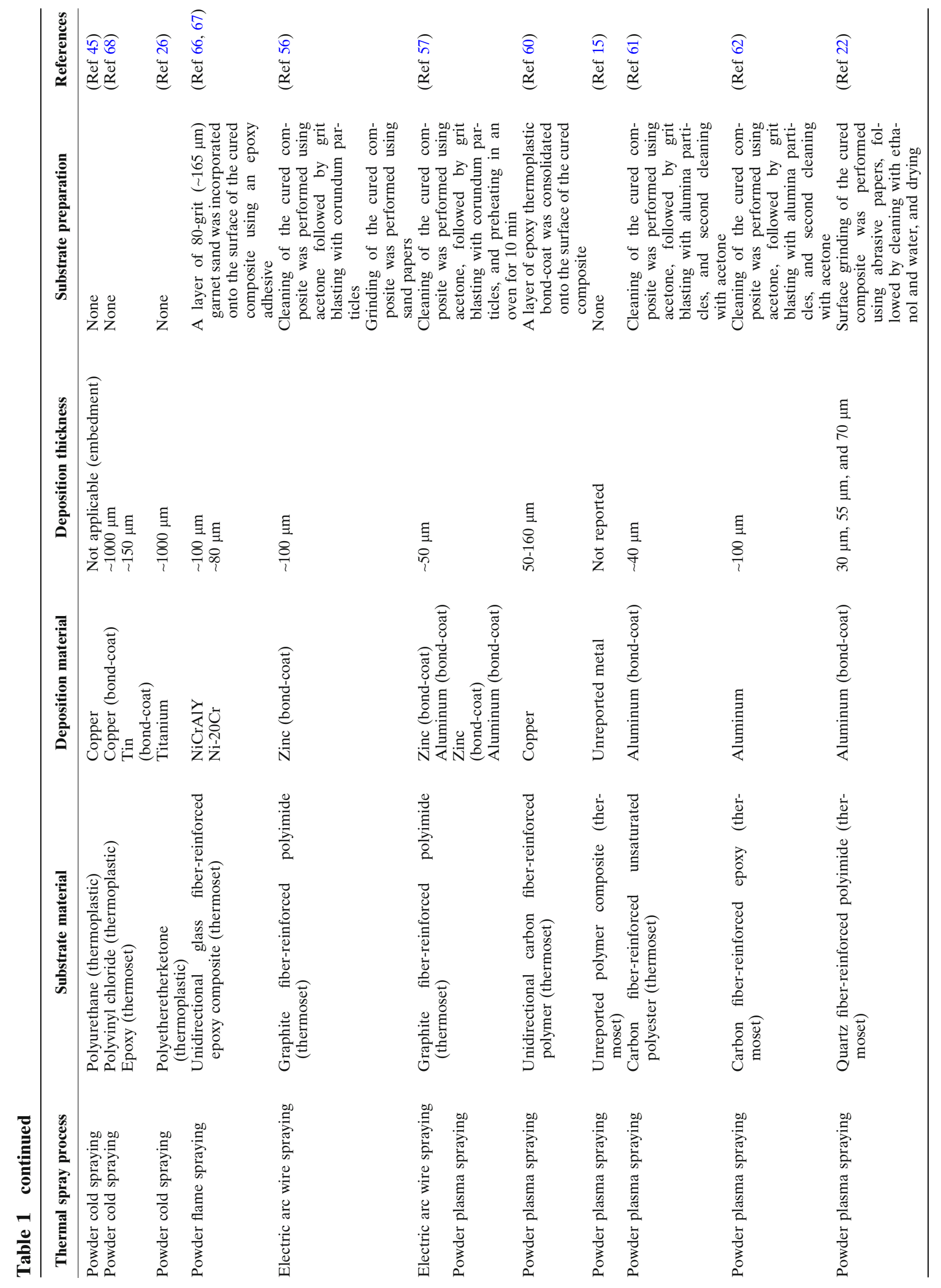




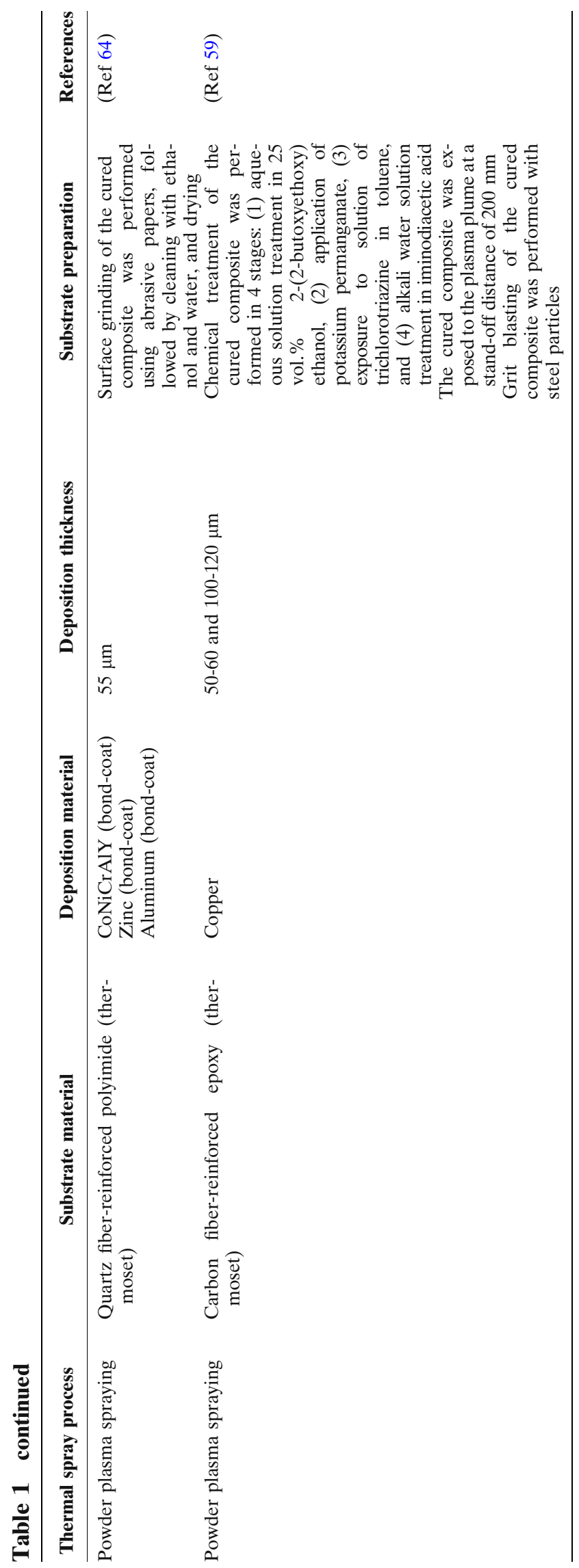

deposition of metal or metal alloy particles at relatively low temperatures; (ii) flame spraying, comprising particle deposition using a combustion flame jet; (iii) electric arc wire spray, which utilizes an electric discharge from electrodes around a carrier gas stream to generate a thermal jet; and (iv) plasma spraying, involving ionized gas jets generated by either direct current (DC) or radio-frequency (RF) current. Each of the thermal spray processes will generate different magnitudes of energy in the fluid heat source that is used to heat and accelerate the particles for deposition. Figure 2 shows the approximate range of gas temperature and particle impact velocity of different thermal spray metallization processes (Ref 2,4$)$. The spray parameters of the reported thermal spray metallization processes are presented in Table 2. A summary of potential applications and characteristic properties of thermal-sprayed metal deposits consolidated onto polymer-based substrates is shown in Table 3.

\subsection{Cold Spraying}

Cold spraying is a relatively low-temperature thermal spray process where solid-state particles are accelerated through a nozzle to high velocities $(300-1200 \mathrm{~m} / \mathrm{s})$, and the coating is formed as a result of plastic deformation and interlocking of the deformed particles upon impact (Ref 2, 9). Cold spray deposition is predominantly based on using the kinetic energy of the impacting particles to promote solid-state plastic deformation and adiabatic shear instability heating, since melting of the feedstock powder material does not occur. However, softening of the impacting particles may develop due to the temperature rise upon impact and deformation of the ductile metal particles (Ref 6,7). Cold-sprayed particles deform plastically upon impact on the substrate at a critical velocity that overcomes rebounding and substrate erosion and produces adhesion (Ref 9, 23, 44). As shown in Table 2, the process parameters of the cold spray process include nozzle geometry, nozzle stand-off distance (distance between the nozzle and the substrate surface), feedstock material, and carrier gas temperature and pressure. Cold spraying is typically performed using a convergent-divergent De Laval nozzle (Ref 9), which accelerates the carrier gas stream to high velocity through expansion of compressed gases.

Although the mechanism of cold spray deposition on polymers is a topic of active research, cold spray metallization has been achieved on polymer-based materials (Ref 9). As adduced from Table 1, cold spray metallization of polymers has been found to be suitable for ductile metals with relatively low melting temperature, hardness, and mechanical strength such as aluminum ( $\mathrm{Al})$, zinc $(\mathrm{Zn})$, and tin (Sn) (Ref 9, 16, 21, 47, 48). The limited thermal energy required in the cold spray metallization of polymers may forestall potentially deleterious effects in as-sprayed parts, such as the accumulation of residual thermal stresses, metal oxidation, and undesired chemical reactions (Ref 9, 49). Robitaille et al. (Ref 16) showed that the use of lower feedstock and carrier gas temperatures can prevent thermal degradation of prepared polymer-based substrates. As a 


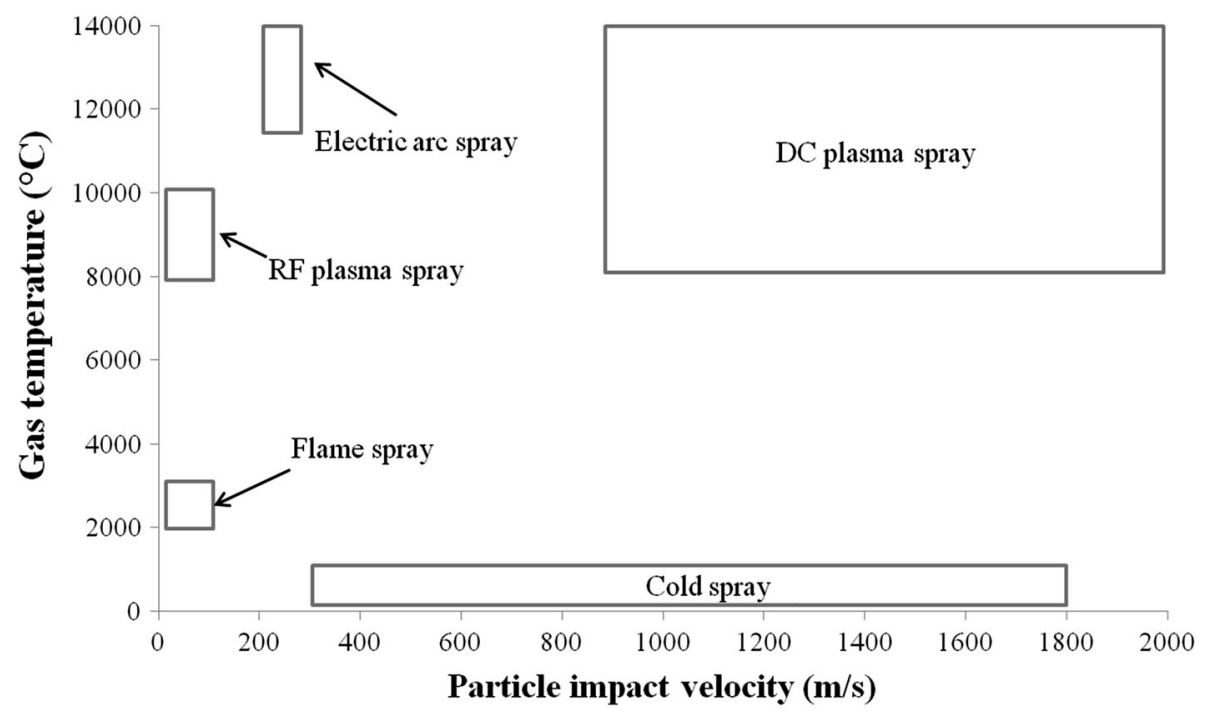

Fig. 2 Gas temperature and particle impact velocity map of several thermal spray metallization processes (Ref 2, 4)

Table 2 Process parameters of thermal spray processes

\begin{tabular}{|c|c|}
\hline Thermal spray process & Spray parameters \\
\hline Cold spraying & $\begin{array}{l}\text { - Feedstock powder } \\
\text { - Nozzle geometry } \\
\text { - Powder feed rate } \\
\text { - Carrier gas pressure } \\
\text { - Gas temperature } \\
\text { - Stand-off distance }\end{array}$ \\
\hline Flame spraying & $\begin{array}{l}\text { - Feedstock powder } \\
\text { - Nozzle geometry } \\
\text { - Powder feed rate } \\
\text { - Carrier gas pressure } \\
\text { - Fuel gas flow rate } \\
\text { - Oxygen flow rate } \\
\text { - Compressed air pressure } \\
\text { - Stand-off distance }\end{array}$ \\
\hline Electric arc wire spraying & $\begin{array}{l}\text { - Arc gun geometry } \\
\text { - Wire material } \\
\text { - Wire feed rate } \\
\text { - Electrical current } \\
\text { - Compressed air pressure } \\
\text { - Stand-off distance }\end{array}$ \\
\hline Plasma spraying & $\begin{array}{l}\text { - Nozzle geometry } \\
\text { - Feedstock powder } \\
\text { - Powder feed rate } \\
\text { - Electrical current } \\
\text { - Plasma gas flow rate } \\
\text { - Compressed air pressure } \\
\text { - Stand-off distance }\end{array}$ \\
\hline
\end{tabular}

result, cold-sprayed metal coatings may be suited for applications related to surface protection and bond-coating (bond-coat) engineering (Ref 21,48 ) on temperature-sensitive polymer structures, such as aerospace-grade carbon fiber-reinforced polymer (CFRP) composites (Ref 16, 49). On the other hand, limited heating of the powder particles by the carrier gas can increase the plasticity of the metal particles (Ref 23, 48), which would, in turn, reduce the critical velocity required for cold spray deposition and particle adhesion (Ref 9). As shown in Table 1, most of the previous studies have utilized low carrier gas temperature to promote cold spray deposition of metals onto thermoplastic substrates, such as Al onto polyamide 66 (PA66) (Ref 24), copper $(\mathrm{Cu})$ and $\mathrm{Sn}$ onto polyvinyl chloride (PVC) (Ref 25), Al onto polycarbonate (PC) (Ref 27), and titanium onto polyetheretherketone (PEEK) (Ref 26).

The cold spray process parameters that are presented in Table 2 influence the gas flow velocity during metal deposition onto polymer-based substrates. Based on the gas flow velocity during the spray deposition process, three types of cold spray processes can be used for metallization of polymers $(\operatorname{Ref} 2,9,16,48)$ :

(a) Low-pressure cold spray (LPCS), in which the gas pressure is below $1 \mathrm{MPa}$ and the particle velocities usually range between 300 and $600 \mathrm{~m} / \mathrm{s}$ (Ref 9). The lower kinetic energy of the particles in the LPCS process can reduce the deposition efficiency of the metallization process since critical velocities of the impacting particles may not be achieved (Ref 2, 50).

(b) High-pressure cold spray (HPCS), in which a carrier gas with low molecular weight such as nitrogen or helium, is utilized and particle velocities are between 800 and $1400 \mathrm{~m} / \mathrm{s}$ (Ref 2, 9). Typical upstream gas pressures range between 1 and $4 \mathrm{MPa}$ (Ref 2, 9, 47).

(c) Pulsed-gas dynamic spraying, in which the carrier gas stream oscillates by way of a series of fixed-frequency shock waves (Ref 51). The shock waves propagate abrupt increments of pressure and temperature in the carrier gas stream that are higher than those of conventional cold spray systems, which produces impacting particles with higher velocities (Ref 9).

The higher kinetic energy of cold-sprayed metal particles can also induce structural damage to the polymerbased structures at the expense of coating fabrication. Robitaille et al. (Ref 16) reported limited substrate abrasion as a result of the deposition of $\mathrm{Zn}$ coatings onto exposed carbon fiber/epoxy composite thermosets using 


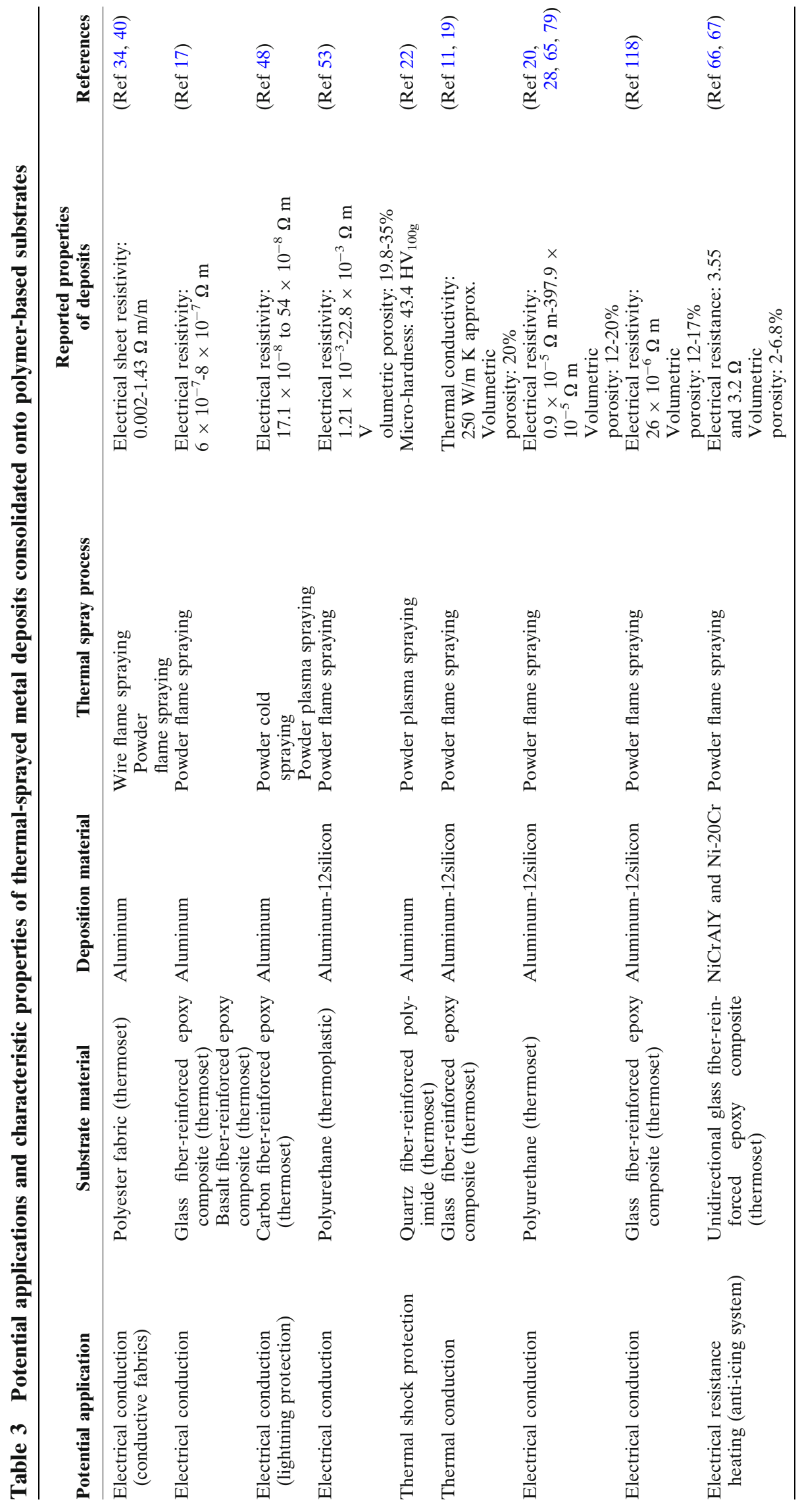


the pulsed-gas dynamic cold spray process. In another study, erosion of thermoplastic substrates, namely polyamide- 6 and a blend of PC and acrylonitrile butadiene styrene (ABS), was observed as a result of cold spray deposition of $\mathrm{Cu}$ particles at high pressure (Ref 47).

Alternatively, HPCS has been used to embed metal particles into polymer-based substrates without the formation of a continuous coating ( Ref 23, 44, 45), as highlighted in Table 1. Embedment of $\mathrm{Cu}$ particles deposited into PU and high density polyethylene (HDPE) thermoplastic substrates has shown potential for antifouling applications. Cold-sprayed embedment studies reported to date have utilized $\mathrm{Cu}$ deposition particles and neat polymer substrates, with carrier gas temperature that ranges between 100 and $400{ }^{\circ} \mathrm{C}$.

\subsection{Flame Spraying}

Flame spraying is a thermal spray process in which the combustion of fluid fuels produces a flame jet that melts and accelerates the feedstock material for deposition onto the substrate. The combustion gases are usually acetylene and oxygen, though air may also be added for cooling purposes (Ref 11). The feedstock particles are propelled toward the substrate through a nozzle by the flow of a carrier gas, which is usually an inert gas such as argon. The feedstock material can be in the form of powder, wire, rod, or cord. The flame temperature should be sufficiently high to ensure the melting of the feedstock material (Ref 2). The flame spray process usually exhibits gas temperatures between 2000 and $3000{ }^{\circ} \mathrm{C}$ (Ref 4, 52), whereas the particle impact velocity is usually below $100 \mathrm{~m} / \mathrm{s}$ (Ref 2). As shown in Table 2, the flame spray process parameters include nozzle geometry, nozzle stand-off distance from the substrate, carrier gas pressure, feedstock material, and combustion gas flow ratio (e.g., fuel-to-oxygen ratio).

Previous studies (Ref 19, 53) have shown that flamesprayed metal coatings can provide functional advantages to polymer-based structures. These functional advantages include enhancement of electrical and thermal conduction properties, as shown in Table 3. Although the flame spray process has been identified as a relatively inexpensive thermal spray metallization process for polymers (Ref 19), the flame-sprayed metal coatings contain levels of higher porosity and, therefore, lower mechanical strength compared to those coating deposited by cold and plasma spraying (Ref 4). Consequently, deposition by flame spraying may require careful execution and optimization of spray parameters to develop suitable and cost-effective functional metal coatings on polymer-based structures. Flame spray deposition of metal coatings onto polymerbased substrates is constrained by the sensitivity of the substrate to the impact of high-temperature, semi-molten, and molten particles (Ref 34). In addition, heat transfer studies indicate that a significant thermal load can be exerted during flame spray metal deposition on to polymerbased substrates (Ref 20).

As shown in Table 1, flame spray metallization of polymer-based substrates has been investigated using $\mathrm{Al}$ and aluminum-12silicon (Al-12Si) powders, the latter consisting of $88 \mathrm{wt} \%$ aluminum and $12 \mathrm{wt} \%$ silicon. Voyer et al. (Ref 34, 40) showed that the surface conductivity of Al coatings deposited onto polyester textile substrates increased proportionally to the coating thickness, while the flexibility of the polymer fabric was retained and was unchanged. Boyer et al. (Ref 53) characterized flame-sprayed Al-12Si coatings deposited onto PU substrates. It was found that Al-12Si coatings with satisfactory bonding and electrical conductivity can be deposited onto PU elastomer up to a threshold coating thickness. Beyond the threshold coating thickness, spalling (peeling) of the metal coating from the substrate occurred. Therefore, flame-sprayed coatings can be used to modify the electrical properties of the polymer substrate, provided that the deposition process does not compromise the structural integrity of as-sprayed structures.

A review of Table 1 shows that other studies have focused on the mechanical behavior of the flame-sprayed metal coatings deposited onto polymer-based substrates. Huonnic et al. (Ref 17) studied the effect of flame-sprayed Al coatings deposited onto grit-blasted basalt and glass fiber composite tubes with a $\left[ \pm 60_{3}^{\circ}\right]_{\mathrm{T}}$ fiber architecture. Significant damage to the FRPC structure was reported as a result of the flame spray metal deposition process. Subsequent studies (Ref 18, 19) utilized a garnet sand interlayer between the FRPC substrate and the flame-sprayed metal particles to protect the temperature-sensitive substrate from the flame and particle impingement forces.

\subsection{Electric Arc Wire Spraying}

Electric arc wire spraying is a thermal spray process whereby the heat generated in an electric arc discharge melts feedstock wires to form droplets, which are accelerated in a gas stream through a nozzle, for deposition onto the substrate (Ref 2, 54). Two feedstock wires with opposing polarity converge at the nozzle outlet at a constant speed to generate the electric arc discharge. The electric arc wire spray process can generate gas temperatures in excess of $5000{ }^{\circ} \mathrm{C}$ (Ref 54), whereas particle impact velocities are usually below $300 \mathrm{~m} / \mathrm{s}$ (Ref 2). Feedstock wires can be made of metals or metal-cored wires (Ref 2). As shown in Table 2, the process parameters of the electric arc wire spray process comprise the arc gun geometry, electrical current input, arc gun stand-off distance from the substrate, carrier gas pressure, and wire material and feed rate (Ref 54, 55).

The electric arc wire spray process has been utilized to deposit $\mathrm{Zn}$ and $\mathrm{Al}$ particles onto polymer-based substrates, as shown in Table 1. Liu et al. conducted two studies (Ref 56, 57) on the arc wire spray deposition of $\mathrm{Zn}$ and $\mathrm{Al}$ bond-coats onto PMC substrates. In these studies, it was found that the metal bond-coat allowed the deposition of a harder and more thermally resistant top coating. As adduced from Table 1, limited research is available on electrical arc metallization of polymer-based substrates, and recent studies have focused on the fabrication and characterization of bond-coats using low melting temperature materials such as $\mathrm{Al}$ and $\mathrm{Zn}$. On the other hand, it should be noted that no studies to date have 
been reported on powder arc spray deposition of metal coatings onto polymer-based substrates.

\subsection{Plasma Spraying}

Plasma spraying is a thermal spray process whereby an ionized gas jet melts and propels the feedstock powder for deposition onto the substrate. The plasma jet consists of a carrier gas that is expanded through a nozzle to create a sub- or supersonic flow (Ref 3,58) while being heated to the ionized gas state by DC arc or RF discharges (Ref 3). Argon, nitrogen, helium, and hydrogen may be used to produce the plasma jet, which reaches a temperature up to $14,000{ }^{\circ} \mathrm{C}(\operatorname{Ref} 43,46)$. Particle impact velocities associated with the plasma spray process are usually between 160 and $2000 \mathrm{~m} / \mathrm{s}$ (Ref $2,4)$. As indicated in Table 2, the process parameters of the plasma spray process include torch geometry, electrical current input, torch stand-off distance from the substrate, plasma gas flow rate, and feedstock material (Ref 2). Plasma spraying is a unique process compared to the other thermal spray processes due to the higher gas temperatures achieved by the plasma jet, which allow the deposition of metals with high melting temperatures.

Plasma spray metallization of polymers has been performed using air plasma spraying (APS). The APS process has been used to deposit $\mathrm{Al}, \mathrm{Zn}$, and $\mathrm{Cu}$ coatings onto PMC parts (Ref 22, 57, 59-61), as evidenced in Table 1. Plasma-sprayed $\mathrm{Al}$ and $\mathrm{Zn}$ bondcoats deposited onto PMC specimens exhibited similar or higher shear adhesion strength compared to that of similar coatings deposited by electric arc wire spraying (Ref 57). On the other hand, it has been noted that the high thermal load exerted by the plasma spray process on the polymer-based substrates can degrade the substrates (Ref 9, 57). Therefore, careful execution of plasma spray metallization of PMC parts should be considered to avoid structural degradation of the substrate.

Limited studies have been conducted on the plasma spray deposition of electrically conductive metals onto polymer-based substrates, as is observed from the information presented in Table 1. Beydon et al. (Ref 60) and Ganesan et al. (Ref 59) reported the APS deposition of $\mathrm{Cu}$ layers onto carbon fiber-reinforced thermosets using chemical, thermal, and mechanical surface preparation of the substrate. Alternatively, Huang et al. (Ref 22) and Guanhong et al. (Ref 61, 62) studied the deposition of thin Al bond-coats onto fiber-reinforced polymers. In these studies, the research focus was on the fabrication, thermal expansion, and mechanical characterization of the metal deposits, as opposed to the investigation of the electrical properties of as-sprayed parts. On the other hand, Affi et al. (Ref 48) reported the deposition of electrically conductive plasma-sprayed Al coatings onto carbon fiber-reinforced epoxy (thermoset) substrates, as indicated in Table 3. Also, plasma spray deposition of metal coatings onto polymer-based air foils for application as de-icing elements has been undertaken in industry (Ref 15). However, the authors of this study did not disclose the spray parameters that were used to fabricate the coatings.

\section{Surface Preparation of Polymer-Based Substrates}

Preparation of the substrate for thermal spraying is essential to promote the adhesion of the impacting particles. The surface preparation process increases the roughness of the substrate surface and promotes the formation of a mechanical bond between the impacting particles and the substrate (Ref 63). Grit blasting is one of the most common methods for roughening the substrate prior to thermal spray deposition. During the grit blasting process, the roughness of the surface increases as a result of the erosion and material removal caused by the impact of high velocity hard grit medium. The application of grit blasting as a pre-treatment technique for thermal spraying is not limited to metal substrates and has been employed to roughen polymer-based substrates. As shown in Table 1, Liu et al. (Ref 56) grit-blasted PMC substrates made from graphite fiber-reinforced thermo-setting polyimide prior to plasma spray deposition, in order to promote the adhesion and fabrication of $\mathrm{Zn}$ coatings. Huonnic et al. (Ref 17) used grit-blasted glass and basalt FRPC tubes to promote the formation of $\mathrm{Al}$ coatings. Guanhong et al. (Ref 61, 62) grit-blasted PMC (carbon fiber-reinforced unsaturated polyester) substrates to promote the deposition of Al bond-coats using APS. Although grit blasting allowed the successful deposition and adhesion of metal coatings in previous studies, this process may not be a suitable method for brittle polymer substrates susceptible to cracking and localized fracture under the impact of high velocity grit media.

Damage induced in the substrate by grit blasting can adversely affect the mechanical properties of polymerbased structures. The results of the study by Huonnic et al. (Ref 17) suggested that grit blasting of FRPC tubes can decrease the burst pressure of composite pipes by compromising the integrity of the reinforcing fibers of the composite. The degree of damage is dependent upon the velocity of the blasting media, which is a function of the control parameters of the grit blasting unit and physical properties of the blast medium. Liu et al. (Ref 56) showed that the level of damage in a graphite fiber-reinforced thermoset polyimide substrate is likely to increase at higher pressures of the carrier air of the blasting medium due to the higher velocity of the impacting particles. On the other hand, difficulties associated with the grit blasting of polymer-based substrates are not limited to the risk of structural damage. Soft and flexible elastomers, such as PU that exhibit high elongation at yield, may cause the grit medium to rebound from the surface as it deforms elastically under the load of the impinging medium. During grit blasting, the roughness of the substrate surface increases as a result of the erosive wear caused by the impact of hard particles. On the other hand, the roughness 
of the substrate surface can also be increased via abrasive wear (i.e., grinding) of the substrate surface (Ref 22, 56, 64). As presented in Table 1, Huang et al. (Ref 22) showed that grinding of the surface of quartz fiber-reinforced polyimide (thermoset) substrates using abrasive paper (mesh size 240) can increase the surface roughness through erosion of the substrate resin and exposure of the fibers. Liu et al. (Ref 56) roughened the surface of graphite fiber-reinforced thermo-setting polyimide substrates by both grinding and grit blasting. The grinding was conducted by using a range of sandpaper mesh sizes from 60 to 1000 . The maximum shear adhesion strength of the coating was obtained by using mesh size 100 , which was lower than that of samples roughened with grit blasting at pressures higher than $0.2 \mathrm{MPa}$. This suggests that irregular surface asperities caused by the impact of high velocity grits can result in mechanical bonds of higher strength between the surfaces and the deposited splats compared to those of abraded surfaces produced by grinding. On the other hand, due to the mechanical damage caused by the abrasion of polymer-based substrates, grit blasting and grinding methods may not be suitable for surface pretreatment prior to the thermal spray process and alternative methods may be warranted.

The addition of a granular material on the surface of the polymer substrate is an alternative method that has been used to increase the roughness of the substrate surface, in lieu of grit blasting. As shown in Table 1, Gonzalez et al. (Ref 18) roughened the surface of glass fiberreinforced epoxy (thermoset) tubes by the addition a layer of garnet sand during the curing process prior to the flame spray deposition of Al-12Si coatings. In contrast to results reported by Hounnic et al. (Ref 17), where the grit blasting process was employed, this technique did not alter the strength of the FRPC tubes and the internal pressure required to cause fracture and damage of the coated FRPC specimens remained unchanged from that of the uncoated FRPC specimens. The addition of a ceramic granular material, with its low thermal conductivity, also provides a barrier to heat transfer from the high-temper- ature flame and particles, protecting the polymer substrate from high-temperature degradation during the thermal spray process (Ref 18). Also, Robitaille et al. (Ref 16) suggested that the granular metal layer can be added to the substrate surface during the curing process of the polymer substrate to promote thermal spray deposition. In this study, a layer of $\mathrm{Cu}$ particles was added onto the unidirectional/weave carbon fiber-reinforced epoxy (thermoset) substrate during the curing process to enable the deposition of cold-sprayed $\mathrm{Zn}$ coatings without inducing any damage to the substrate fibers. Deposition on the substrate with no surface pre-treatment led to erosion of epoxy and exposure and damage of the carbon fibers. The idea of incorporating granular material on the surface of the polymer substrates during the curing process has also been employed for deposition of conductive coatings onto elastomers such as PU. Boyer et al. (Ref 53) roughened the castable PU (thermoset) surface by the addition of $\mathrm{Cu}$ particles during the curing process, as shown in Table 1 . It was found that flame-sprayed Al-12Si particles interlocked with the $\mathrm{Cu}$ particles to form a continuous electrically conductive coating. In another study conducted by Ashrafizadeh et al. (Ref 28, 65), the addition of the same metal powder as that of the spraying powder was suggested to roughen the thermo-setting PU substrate during the curing process, which ensured consistency between the roughening agent and the deposited particles. In another study by Lopera-Valle and McDonald (Ref 66, 67), it was shown that the layer of granular sand material can also be added to the thermosetting substrate (glass fiber-reinforced epoxy composite) surface by applying a layer of adhesive after the curing process, which allowed the deposition of coatings consisting of $80 \mathrm{wt} \%$ nickel and $20 \mathrm{wt} . \%$ chromium (Ni-20Cr). Figure 3 shows a cross section image of the deposited Ni-20Cr coating and the sand layer added onto the FRPC substrate. As evidenced in Fig. 3, the metal coating and the granular particles used for roughening the polymer-based substrate are bound by mechanical interlocking.

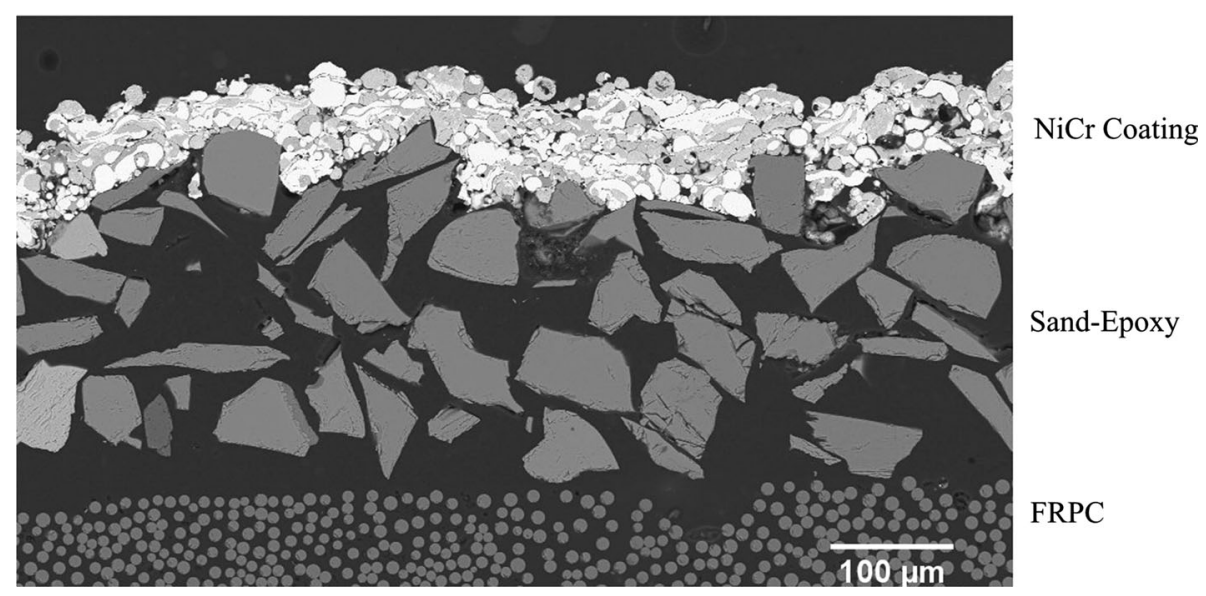

Fig. 3 Backscattered scanning electron microscope (SEM) image of the cross section of a flame-sprayed Ni-20Cr coating deposited onto a fiber-reinforced polymer composite (FRPC) substrate (Ref 67) 
On the other hand, the deposition of thermally sprayed coatings onto polymer-based substrates without surface preparation has also been reported in the literature (Ref $21,25,40,47,68)$. In cold spraying, the sprayed particles were heated to temperatures below the melting temperature of the powder material. Thus, the metal particles are stiffer and may penetrate the soft polymeric substrates when accelerated to high velocities. Also, process parameters can allow the hot carrier gas to soften the polymer-based substrate beyond the threshold of penetration for impinging metal particles, resulting in particle penetration into the substrate and ultimate adhesion. The sprayed particles would form a mechanical bond with the deposited metal particles already attached to the polymerbased substrate.

\section{Deposition of Metal Bond-Coat}

It is desirable to select a thermal spray process that allows the deposition of metals with low porosity and oxide levels, while avoiding the deleterious thermal effects that are common during deposition on polymer substrates. Most heat resistant polymers, such as polytetrafluoroethylene (PTFE), have a thermal decomposition temperature not higher than $470{ }^{\circ} \mathrm{C}(\operatorname{Ref} 69)$. The fact that the temperatures involved in thermal spray processes can be as high as $14,000{ }^{\circ} \mathrm{C}$ (see Fig. 2) illustrates the challenge of performing the thermal spray metallization of structural polymer-based substrates. Hence, monitoring and control of the temperature within the substrate during thermal spray deposition onto polymer-based materials are of interest.

In the case of deposition of powder particles with high melting temperatures, regardless of the heat produced by the spray plume, localized degradation of the polymer substrate can occur as a result of the impact of hightemperature particles. Under these circumstances, fabrication of an intermediate metal coating with lower melting temperature particles can be advantageous. As presented in Table 1, Guanhong et al. (Ref 61) deposited an Al bond-coat onto carbon fiber-reinforced unsaturated polyester (thermoset) substrate prior to deposition of the final aluminum oxide $\left(\mathrm{Al}_{2} \mathrm{O}_{3}\right)$ coating by APS. This technique allowed for enhanced protection of the polymer substrate from the high temperatures of the molten and semi-molten $\mathrm{Al}_{2} \mathrm{O}_{3}$ particles and the high temperature of the plasma spray deposition process. Aluminum bondcoats deposited at shorter stand-off distances and higher plasma currents were found to have higher adhesion strength. This was due to the greater deformation exhibited by splats and the overall improvement in morphology that led to a denser structure of the coating. Similarly, Table 1 shows that Huang et al. (Ref 22) deposited $\mathrm{Al}$ as a bond-coat prior to spraying the final yttria-stabilized zirconia (YSZ) coating in an effort to protect the quartz fiber-reinforced polyimide (thermoset) substrate from the high temperature of the plasma-sprayed YSZ deposition particles. However, it was further shown by Huang et al., (Ref 64) that the use of $\mathrm{Zn}$ as a bond-coat provided better thermal protection for the polymer substrate. This was likely due to the lower thermal conductivity of $\mathrm{Zn}$ of approximately $116 \mathrm{~W} / \mathrm{m} \mathrm{K}$ in comparison to that of $\mathrm{Al}$ of approximately $237 \mathrm{~W} / \mathrm{m} \mathrm{K}(\operatorname{Ref} 70)$. The thermal expansion coefficient of $\mathrm{Zn}$ is also lower than that of Al. As a result of the deposition of the $\mathrm{Zn}$ bond-coat, the final deposited coating showed higher thermal shock resistance compared to that of $\mathrm{Al}$ bond-coat. Thus, deposition of a suitable bond-coat can reduce the adverse thermal effects of thermal spray metallization of polymer-based substrates. Liu et al. (Ref 57) studied the effect of the bondcoat material on the microstructure and shear adhesion strength of plasma-sprayed coatings deposited onto graphite fiber-reinforced polyimide (thermoset) substrates. It was found that materials with higher melting temperature, such as $\mathrm{Cu}$ (melting temperature of $1083^{\circ} \mathrm{C}$ ) and nickel (melting temperature of $1453{ }^{\circ} \mathrm{C}$ ), produced thermal damage on the polymer-based substrate (polyimide with working temperature of $371{ }^{\circ} \mathrm{C}$ ) upon deposition. This thermal damage affected the bond strength between the carbon fibers and the polyimide matrix, which led to separation of some fibers and a weak bonding at the coating-substrate interface. The bond-coats of materials with lower melting temperature, such as Al (melting temperature of $660^{\circ} \mathrm{C}$ ) and $\mathrm{Zn}$ (melting temperature of $418^{\circ} \mathrm{C}$ ), did not delaminate from the substrate. However, in the case of $\mathrm{Al}$, localized broken fibers with thermally damaged regions between the substrate and the Al bondcoat were observed, whereas for $\mathrm{Zn}$ bond-coats, no evident damage on the substrate was produced. This can be explained by the lower melting temperature of $\mathrm{Zn}$, which was only slightly higher than the long-term service temperature of the polyimide-based substrate of $371^{\circ} \mathrm{C}$.

\section{Thermal Spray Process Parameters}

The properties of thermal-sprayed coatings are a function of the spraying parameters. Thermal spray parameters can be considered as the process inputs that affect the particle velocity, particle temperature, and substrate temperature. The substrate temperature is of particular importance when depositing on substrates with a low heat capacity, such as polymer-based materials. In this case, the spraying parameters not only affect the morphology of the final deposited coating, they also affect the level of damage that the substrate might experience during the thermal spraying process.

Thermal spray processes allow for different ranges of deposition parameters (see, for example Fig. 2). The appropriate selection of the thermal spray process parameters should be considered in the context of thermal spray metallization of polymer-based materials. Liu et al. (Ref 57) showed that the arc spraying process is not suitable for metal coating deposition onto graphite fiber-reinforced polyimide (thermoset) substrates given that the tip of the feeding wire must be heated beyond its melting point to form droplets for deposition. As a result of overheating of $\mathrm{Al}$ droplets by arc spraying, the formation of 
thermal damage regions on the substrate has been reported. Therefore, the control on the temperature of the arc-sprayed particles is limited compared to that of other thermal spraying processes such as flame spraying, in which the temperature of the spray plume can be controlled independently to avoid over-heating the impinging metal particles.

Table 2 summarizes the process parameters of thermal spray metallization processes for polymer-based structures. Values of these parameters should be selected based on the physical properties of the sprayed particles, the required temperature and velocity for particle deposition, and the substrate heat capacity. Consequently, spraying parameters such as the electric current input in plasma and arc spraying, and fuel and oxygen feeding rates in flame spraying should be apt to ensure that the produced thermal load will not compromise the integrity of the polymer substrates. Guanhong et al. (Ref 61) studied the effect of the plasma spray current on the quality of the coatings deposited onto polymer substrates. It was shown that the use of high currents and long spraying times during plasma spraying of $\mathrm{Al}_{2} \mathrm{O}_{3}$ introduced thermal damage to carbon fiber-reinforced unsaturated polyester (thermoset) substrates even with pre-deposition of $\mathrm{Al}$ as bond-coat. A higher current increases the energy and velocity of the plasma jet, which would lead to greater absorption of the incident energy from the plasma jet and the impacting high-temperature particles by the substrate. Other spraying parameters such as air cooling and modifying the stand-off distance between the thermal spray heat source and the substrate can be employed for further process control. It has been found that the stand-off distance influences the metal coating deposition onto polymer-based substrates (Ref 34, 40). Shorter stand-off distances led to shorter in-flight time of the metal particles and, therefore, they had higher impact velocity and temperature and reduced oxide content. On the other hand, shorter stand-off distances produce a higher heat flux into the substrate, increasing the temperature within that substrate (Ref 71). This increases the risk of imposing excessive thermal load onto heat sensitive substrates such as polymer-based materials. Thus, although shorter standoff distance can lead to higher deformation of splats and improved coating morphology, setting the stand-off distance to very low values is not recommended for thermal spray deposition onto polymer-based materials, unless temperature control methods such as air cooling are used.

The injection of compressed air during the thermal spraying process is an effective method to cool the substrate and limit thermal damage induced by the thermal spray deposition process. As shown by Floristan et al. (Ref 72), air cooling was utilized to reduce the thermal load on the substrate and prevent the coating from cracking during plasma spraying of $\mathrm{TiO}_{2}$ coatings onto glass substrates. The addition of compressed air can protect the substrate from residual-stress induced cracking by reducing the thermal load and temperature within the substrate and allow thermal spray deposition at shorter stand-off distances. As a result of shorter stand-off distances, coatings with lower electrical resistance were deposited due to the reduction in oxidation, higher deformation and improved interlocking of splats and lower porosity of the $\mathrm{TiO}_{2}$ coating (Ref 72). The technique of employing additional air cooling during the thermal spraying process to control the temperature within the substrate has been shown to be applicable to polymer-based substrates as well. Ashrafizadeh et al. (Ref 28, 65) studied the effect of the addition of compressed air to the flame spray nozzle for deposition of Al-12Si coatings on PU substrates. It was shown that the addition of compressed air decreased the coating porosity and reduced the electrical resistance of the deposited coatings due to the impact of droplets with higher velocity and higher deformation of splats. The authors also showed that temperature control within the substrate was possible by reducing the stand-off distance while increasing the pressure and flow rate of the compressed air. As a result of using shorter stand-off distances, denser coatings with improved morphology (greater deformation of splats and improved mechanical interlocking) and higher electrical conductivity were fabricated. In another study, Voyer et al. (Ref 34, 40) utilized air cooling of the substrate during the deposition of flame-sprayed Al coatings onto substrates made of polyester woven fabric (thermoset), as shown in Table 1. It was shown that by introducing cool air and optimizing the spraying parameters, the stand-off distance could be reduced without imposing any evident thermal damage to the polymerbased substrate. This technique allowed the fabrication of metal coatings with improved morphology as a result of augmented thermal conductivity at shorter stand-off distances during flame spray deposition. Although the use of compressed air cooling reduced the temperature within the unfilled PU (Ref 28, 65) and polyester fabric (Ref 34, 40) substrates during flame spraying, future research to evaluate the efficiency of this technique in reducing the thermal load on polymer composite substrates such as fiber-reinforced polymers will be of interest.

Similar to other thermal spray metallization processes, cold spray parameters play an important role on the final characteristics of the deposited coating and possible mitigation of damage of the polymer-based substrate. As shown in Table 1, Ganesan et al. (Ref 25) explored the feasibility of the cold spray process for the deposition of $\mathrm{Cu}$ and $\mathrm{Sn}$ coatings onto PVC (thermoplastic) substrates. It was shown that the gas temperature affects the coating deposition efficiency, possibly due to the thermal softening of the PVC substrate. Thermal softening of the substrate occurred under conditions in which the gas temperature exceeded the glass transition temperature of the PVC substrate $(353 \mathrm{~K})$ and changed the condition of the substrate from rigid to a rubbery state. It was further shown that Sn powder particles had higher deposition efficiency than $\mathrm{Cu}$ particles due to the soft nature of $\mathrm{Sn}$ and its lower impact energy compared to that of $\mathrm{Cu}$. In a subsequent study, Ganesan et al. (Ref 68) evaluated the effect of substrate type on the deposition efficiency of cold-sprayed $\mathrm{Cu}$ and $\mathrm{Sn}$ particles, using thermoset epoxy and thermoplastic PVC substrates. It was found that brittle epoxy substrate exhibited a lower coating deposition efficiency compared to that of PVC. Fracture of the 
epoxy substrate was observed during cold spray deposition, whereas the soft PVC substrate allowed the penetration of impacting particles, which resulted in higher deposition efficiency (Ref 68). Thermal softening of carbon fiber-reinforced PEEK450CA30 (thermoplastic) substrates caused by the high temperature of gas during cold spray deposition of $\mathrm{Al}$ powder has also been reported by Zhou et al. (Ref 21). The softening of the PEEK450CA30 matrix was found to be responsible for the penetration of Al particles into the FRPC material and the formation of a mechanical bond between $\mathrm{Al}$ particles and the polymerbased substrate (Ref 21). Thus, depending on the mechanical properties of the substrate and the cold spray parameters, particles with high velocity either rebound from or penetrate into the substrate (Ref 44). In a comprehensive study by King et al. (Ref 44), the embedment of copper particles into a series of thermoset substrates, namely polyamide (nylon), PU, HDPE, PTFE, PC, and polypropylene (PP) was investigated. The $\mathrm{Cu}$ particles were embedded into the polymer substrates by increasing the gas temperature from 150 to $350{ }^{\circ} \mathrm{C}$. The maximum penetration depth occurred in the PU (softest material) and HDPE (lowest melting temperature). However, due to the softening of the substrates that were studied, the $\mathrm{Cu}$ particles did not deform properly to form a continuous coating. Similarly, in a study conducted by Gardon et al. (Ref 26), it was found that due to the softening of the substrate (bio-compatible PEEK thermoplastic), the coldsprayed titanium particles penetrated (anchored) into the substrate in the absence of coating build-up. A balance between the carrier gas temperature and the thermal softening of the polymer substrate was experimentally found to allow the deposition of titanium coatings. Another study conducted by Lupoi et al. (Ref 47) showed that $\mathrm{Cu}$ and $\mathrm{Al}$ powder particles are not suitable for cold spray metallization of polymer-based substrates such as PC/ABS blend, polystyrene, polyamide-6, and PP substrates by the cold spray process. The high density of $\mathrm{Cu}$ particles led to high impact energy and erosion of the polymer substrates, resulting in higher erosion rates at higher gas pressure. Fabrication of $\mathrm{Al}$ coatings was unattainable since the required critical velocity for cold spray deposition of Al particles was not achieved for the given substrates and process parameters. On the other hand, Sn, with lower specific weight and melting temperature was successfully deposited onto all tested polymerbased substrates of the same study (Ref 47). Therefore, alongside the carrier gas temperature, the feedstock particle material properties have a significant effect on the deposition of cold-sprayed metal coatings onto polymerbased substrates. If the gas temperature is not sufficiently high so as to soften the impacting particles, the high velocity, rigid particles may either penetrate or erode the substrate upon impact. However, introducing excessive heat during the cold spray deposition process can soften the substrate and limit the particle impact energy that remains available for particle deformation, adiabatic shear instability heating, and ultimate adhesion. In general, knowledge of the particle velocity and substrate temperature distribution during the thermal spray deposition process can facilitate the experimental approach to find optimum spray parameters for the deposition of metal coatings onto polymer-based substrates.

\section{Temperature Distribution Within the Polymer-Based Substrate During the Thermal Spray Process}

Most studies focused on thermal spray metallization of polymers have not examined the temperature distribution within the substrate during the spraying process and the possible effect of spraying parameters, such as compressed air pressure and stand-off distance on the temperature distribution. In fact, the spray parameters have usually been obtained on a trial-and-error basis by evaluation of the morphology, characterization of the deposited coatings, and investigation in search of evidence of possible thermal damage in the substrate. Models that can predict the temperature distribution within the polymer-based substrate during the thermal spray deposition process can be used to ensure that the temperature is maintained below the threshold of the thermal load that will cause substrate degradation. In addition, knowledge of the effect of spraying parameters, such as cooling air pressure and stand-off distance on the substrate temperature distribution can facilitate optimization of the thermal spray process. This section provides a summary of the reported models for the determination of the temperature distribution within the substrate during the thermal spray process, considering substrate materials with homogenous thermal properties.

Irrespective of the type of substrate material, the determination of the temperature distribution within the substrate during the thermal spray process requires the solution of a transient heat conduction problem. The heat sources in the thermal spray processes are the heat from the spray plume and the deposited particles. The finite element (FE) method has been used to determine the temperature distribution within the substrate during the thermal spraying process. Hugot et al. (Ref 73) developed a two-dimensional FE model to determine the temperature distribution within the substrate and the resulting residual stresses in the coating during the plasma spraying process, whereas Chen et al. (Ref 74) used FE modeling to model the electric arc spraying process. Moreover, the finite difference numerical method has been used to simulate the heat transfer in thermal spray processes (Ref 7577). Using the finite difference method, Zhu et al. (Ref 75) modeled the electric arc spray deposition process, whereas Bao et al. (Ref 76) modeled flame spraying. To avoid the limitations of numerical methods that involve meshing, Wu et al. (Ref 78) developed a model based on a meshless local Petrov-Galerkin approach to simulate the plasma spray process. The model was verified experimentally and the influence of the stand-off distance on the substrate temperature was shown. Although the proposed numerical methods have been found to be reliable for the prediction of temperature distribution within the substrate 
during spraying, analytical models have been shown to be simpler and more efficient in application. Ashrafizadeh et al. (Ref 20,79) presented an analytical model based on the Green's function approach to determine the temperature distribution within a polymer-based substrate during flame spray deposition. The effect of stand-off distance and air cooling of the flame on the temperature distribution within the substrate was investigated. Non-dimensional parameters for the determination of the temperature distribution within the substrate during the thermal spraying process were also proposed, and the results are illustrated in Fig. 4 (Ref 20, 79). The graph was determined based on the assumption of an insulated surface on the back of the substrate. The model was experimentally verified and was found to be valid for the periods of non-dimensional time, $t^{*}$, smaller than 0.25. In Fig. 4, $T^{*}, x^{*}$, and $t^{*}$ are defined as

$T^{*}=\frac{T-T_{0}}{\frac{q^{\prime \prime} L}{k}}$

$t^{*}=\mathrm{Fo}=\frac{\alpha t}{L^{2}}$

$\alpha=\frac{k}{\rho C_{p}}$

$x^{*}=\frac{x}{L}$,

where $T, T_{0}, q^{\prime \prime}, L, k, \alpha, \rho, C_{\mathrm{p}}, t$, and $x$ are the transient temperature, initial temperature, torch heat flux, substrate thickness, thermal conductivity, thermal diffusivity, density, specific heat capacity, time and position from the substrate surface, respectively. The fact that polymerbased materials have low thermal conductivity (less than $10 \mathrm{~W} / \mathrm{m} \mathrm{K}$ even for most of the composite materials with high thermal conductivity fillers) (Ref 80-84) suggests that the non-dimensional parameter of time $\left(t^{*}\right)$ may also be smaller than 0.25 for many spray conditions on polymerbased materials. This may allow for the determination of the temperature distribution within polymeric substrates during the thermal spray metallization process by using the graph presented in Fig. 4.

The proposed modeling techniques can be used for determination of temperature distribution within substrates with homogenous thermal properties during the thermal spraying process. On the other hand, the proposed models may be limited in their representation of materials exhibiting anisotropic thermal properties. This condition can occur in fiber-reinforced polymer matrix composites based on the arrangement of fibers and differences between the thermal conductivity of the matrix and fiber materials. The temperature distribution in anisotropic substrates may not be one-dimensional and the spatial variation of the thermal conductivity should also be considered in the model formulation. Thus, additional research is required to provide accurate models of the temperature distribution within anisotropic polymerbased substrates during the thermal spraying process.

\section{Testing and Characterization of Thermal-Sprayed Metal Coatings Deposited on Polymer-Based Substrates}

The testing and characterization of thermal-sprayed coatings are important parameters in the evaluation of the quality and properties of the deposited materials, and therefore, are important to determine the performance of coatings in the various applications in which they are used. A combination of materials science and engineering techniques is used to evaluate the mechanical, thermal,

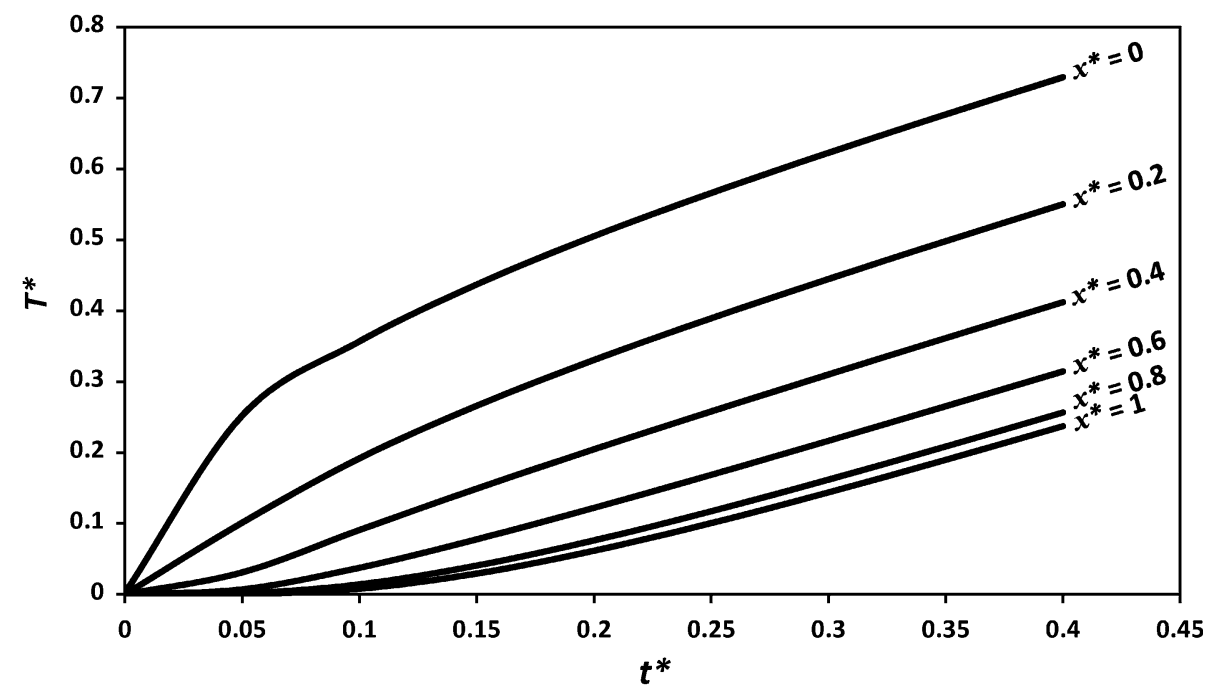

Fig. 4 Curves of the non-dimensionalized temperature as a function of non-dimensionalized time for different positions within a polyurethane substrate during flame spray heating (Ref 20) 
structural, and chemical properties of the thermal-sprayed metal coatings that are deposited on polymer-based substrates. Various techniques have been utilized for the characterization of thermal-sprayed coatings deposited onto polymer-based substrates, including hardness test (Ref 85), Scanning Electron Microscope (SEM) (Ref 46), and x-ray diffraction (XRD) (Ref 86), to name a few. In addition, experimental techniques have been developed to assess the performance of the thermal-sprayed coatings based on specific applications, such as thermal shock protection (Ref 64) and antifouling resistance (Ref 23). Testing and the characterization of thermal-sprayed metal coatings can be accomplished by using general characterization methods and application-based techniques. This section focuses on the techniques that have been used in the characterization of thermal-sprayed coatings deposited onto polymer-based substrates.

\subsection{General Characterization Methods}

7.1.1 Hardness Test. Hardness tests measure the resistance of materials to deformation under a localized load (Ref 46, 87, 88). Given that hardness is a widely used property in materials evaluation, several studies have focused on hardness evaluation methods for most engineering materials, including thermal-sprayed metal coatings (Ref 46, 88, 89). In addition to the measurement of hardness, mechanical properties such as Young's modulus, bond strength, and fracture toughness can be measured through hardness tests that are coupled with various analytical techniques and models (Ref 87, 89-91). ASTM Standard E384 (Ref 85) describes guidelines for performing hardness tests on common materials, including metals and polymers, using Knoop and Vickers indenters.

The Vickers micro-hardness test constitutes the most frequently used technique for measuring the hardness and elastic constants of thermal-sprayed metal coatings, using loads that are between 100 and $500 \mathrm{~g}$ (Ref 46, 88, 89, 92). The Vickers micro-hardness equipment consists of a pyramidal-shaped diamond indenter with an angle between faces of $136^{\circ}$ that produces a square-shaped indentation. The test is done at a pre-set load and dwell time on the surface of the polished coating (Ref 85). The distance between the corners across the square-shaped indentation is used to determine the hardness of the coating. Vickers micro-hardness has been previously used in the characterization of thermal-sprayed coatings over polymer-based composites. For instance, Zhou et al. (Ref 21) performed Vickers micro-hardness testing to characterize a bi-layer cold-sprayed $\mathrm{Al} / \mathrm{Cu}$ coating deposited onto carbon fiber-reinforced PEEK. Vickers micro-hardness tests were performed in the Al bond-coat layer first and following the deposition of the subsequent $\mathrm{Cu}$ top layer. It was noted that the hardness of the Al layer increased by more than $20 \%$, from $42 \mathrm{HV}_{0.1}$ to $52 \mathrm{HV}_{0.1}$, after the deposition of the $\mathrm{Cu}$ layer. This was attributed to the work hardening (compressive) effect of the impacting $\mathrm{Cu}$ particles with high kinetic energy on the $\mathrm{Al}$ bond-coat during the deposition of the top coating layer. The observed reduction in the porosity of the Al bond-coat layer, from 2.9 to $1.1 \%$, following the deposition of the $\mathrm{Cu}$ top layer also explains the increase in hardness. The hardness of the $\mathrm{Cu}$ layer was found to be $140 \mathrm{HV}_{0.1}$, which was reported to be approximately on the same order of that of rolled copper (Ref 21).

Micro-hardness indentation differs from macro-hardness testing, which involves indenter loads between 1 and $100 \mathrm{~kg}$, and exhibit an indentation depth on the same order of magnitude as that of the thickness of the thermalsprayed coating (Ref 46). Therefore, macro-hardness measurements made on the top surface of thermalsprayed coatings may be affected by the mechanical properties of the substrate (Ref 93, 94). As a result, the reliability and repeatability of macro-indentation measurements on the top surface of thermal-sprayed metal coatings is constrained (Ref 85). In this regard, ASTM Standard E384 specifies that the thickness of the material exposed to hardness testing should be at least ten times the indentation depth (Ref 85). Given that typical thermal-sprayed coatings have thicknesses between 100 and $1000 \mu \mathrm{m}$, the indentation resulting from a macro-hardness test would likely exceed one-tenth of the coating thickness, which contravenes the requirements ASTM Standard E384. Therefore, macro-hardness characterization of thermal-sprayed metal coatings deposited onto polymerbased substrates is limited, and careful execution of indentation measurements is required. Similarly, nanoindentation may be performed to measure the hardness of thermal-sprayed metal coatings exhibiting a thickness lower than $100 \mu \mathrm{m}$ and to evaluate the local mechanical properties (i.e., individual deposited splats) in the lamellar and heterogeneous microstructure of the coating. In this case, the macroscopic effects of porosity and intra-particle bonding on the hardness of the thermal-sprayed metal coating would be less evident from nanoindentation measurements (Ref 95). Even though multiple nanoindentation measurements may be used to estimate the hardness of thermal-spayed coatings, this technique has not been reported in regard to the characterization of thermal-sprayed metal coatings deposited onto polymerbased substrates.

As previously mentioned, hardness tests can be used in the measurement of mechanical properties such as Young's modulus, bond strength, and fracture toughness. For instance, Beshish et al. (Ref 96) implemented indentation techniques in the evaluation of the fracture toughness of YSZ coatings by measuring the dimensions of indents in the coatings and the length of the surrounding fracture cracks. This technique can be applied to metallic coatings deposited onto polymer-based substrates exhibiting suitable stiffness (i.e., no creeping under the force of the indenter).

7.1.2 Bond Strength. The bond strength of thermalsprayed metal coatings defines their response to compression and shear loads, and the mechanical integrity of the coating on the substrate (Ref 89, 97). Various bonding mechanisms are involved in defining the bond strength of a coating to the substrate (Ref 90,97-100), and some include (i) mechanical interlocking when the coating material penetrates into the rough asperities of the substrate 
surface (Ref 100, 101), (ii) chemical reaction when the coating and substrate chemically react to form metallurgical bonds (Ref 90), and (iii) solid-state diffusion, also forming metallurgical bonds (Ref 90). It is challenging to quantify the contribution of each mechanism to the total bond strength of the coating to the substrate; therefore, the measurement of the bond strength is accomplished by considering the overall impact of all the mechanisms. The estimation of the coating bond strength allows for evaluation of the integrity of the coating-substrate interface, usually referred to as adhesion, and the strength of the coating within itself, referred to as cohesion (Ref 46, 100).

Several techniques have been used to measure the bond strength of thermal-sprayed metal coatings deposited on polymer substrates. The stud-pull test is a commonly used method in which a loading element (stud) is bonded to the flat surface of the coating, and placed in tension with a load applied at a controlled rate while measuring the displacement of the stud until delamination of the coating occurs (Ref 25, 99, 100, 102). For instance, Ganesan et al. (Ref 25) evaluated the effect of different substrate preparation treatments on the bond strength of plasma-sprayed $\mathrm{Cu}$ coatings, using stull-pull tests. Chemical, thermal, and mechanical surface preparation treatments were compared in this study. Aluminum studs, with $6 \mathrm{~mm}$ in diameter, were bonded to the coatings and pulled using a universal tensile test machine. This study showed that with a strength adhesion of $2.6 \mathrm{MPa}$, the chemical surface preparation treatment presented higher adhesion strength than that presented by the thermal and mechanical treatments, with 1.7 and $2.2 \mathrm{MPa}$, respectively. It was found that adhesive failure was predominant, presenting a complete removal of the coating in the area to which the studs were bonded. Different studies have found that the failure of metal coatings on polymer-based substrates is predominantly adhesive (Ref 25, 60, 100). Nevertheless, cohesive failure has also been reported (Ref 57). Specific procedures and guidelines for performing adhesion strength tests of metallic coatings using portable adhesion testers are described as part of the ASTM D4541 Standard (Ref 102).

The bond strength of thermal-sprayed metal coatings estimated by the tensile adhesion test is based on the ultimate stress and strain (Ref 49, 57, 103, 104). Other test methods for evaluation of the bond strength of deposited coatings are the peel test (Ref 105, 106), laser shock adhesion test (Ref 24, 107-109), and multi-layer three point bending test (Ref 60, 89). However, the application of these other methods on thermal-sprayed coatings deposited on polymer-based substrates has not been widely explored and further research is needed.

7.1.3 Chemical and Phase Composition. The phase composition of thermal-sprayed coatings has been evaluated using x-ray diffraction (XRD) technique in several previous studies (Ref 11, 22, 86, 88, 110, 111). For instance, Osorio et al. (Ref 111) used XRD spectroscopy to characterize the phase transformation of plasma-sprayed YSZ after exposure to temperatures as high as $1100{ }^{\circ} \mathrm{C}$ for up to $1000 \mathrm{~h}$. In addition, the XRD technique has been used to evaluate changes in the phase composition of the deposited material as a result of the high-temperature in thermal spray process (Ref 88,110$)$. The comparison between the material phases in the coating and those of the feedstock material can provide information about any phase transformations (i.e., chemical reactions or oxidation) that occurred during the thermal spray deposition process. In a study conducted by Chen et al. (Ref 110), $\mathrm{XRD}$ was used to compare the material phases of the Al$\mathrm{Al}_{2} \mathrm{O}_{3}$ powder feedstock and the resulting flame-sprayed coating deposited onto a polyurethane substrate. The use of XRD enabled finding a higher content of the $\mathrm{Al}_{2} \mathrm{O}_{3}$ phase in the thermal-sprayed coating, which was possibly due to the oxidation of $\mathrm{Al}$ particles during the high-temperature deposition (Ref 110).

In addition to material phase identification, elemental analysis is important in the characterization of thermalsprayed coatings. Energy dispersive x-ray spectroscopy (EDX), usually coupled with scanning electron microscopy, can be used to determine the elemental composition of thermal-sprayed coatings (Ref 86).

7.1.4 Microstructural Analysis. Knowledge of the morphology and distribution of splats, voids, and cracks in thermal-sprayed coatings can be obtained from microstructural characterization, which is usually performed by evaluating a sample specimen of material using equipment for microscopy and porosimetry (Ref 112). Microstructural analysis can be used to evaluate the porosity and lamellar splat morphology of thermal-sprayed metal coatings deposited onto polymer-based structures. These characteristics of the coating are affected by the spraying parameters, substrate surface conditions, and feedstock material properties and morphology (Ref 2, 4, 13).

Measurement of the porosity in thermal-sprayed coatings is a significant element of microstructural characterization. Pores are three-dimensional defects (voids) in the thermal-sprayed metal coating that can be classified as (i) inter-splats defects, generated as a result of a gap between two different particles, (ii) intra-splat defects, inside the splats, generated from fragmentation of the particles during the deposition process or as result of thermal stresses during the deposition and cool-down of the deformed particles or splats, and (iii) coating delamination defects caused by damage of the coating at either the inter- or intra-splat locations (Ref 9, 46, 88). Some techniques to measure the microstructural porosity within the coating include the use of a volume of fluid to occupy the voids spaces as a mean of measuring the volume of the pores (Ref 46, 88). Examples of the fluid-based measurement methods to estimate the pore volume, and ultimately the porosity, include mercury infusion porosimetry, gas pycnometry, and water absorption (Ref 113, 114). However, microscopy and digital image analysis are more frequently used for the characterization of porosity and the microstructure of thermal-sprayed metal deposits on polymers. In some respects, microscopy and digital image analysis can provide additional information about the coating microstructure including the distribution of pores and location of cracks (Ref 46, 88). For instance, SEM allows qualitative identification of the splat morphology, the degree of interlocking between the coating and 
substrate, and the existence of contaminants and oxides; additionally, high-resolution SEM images can be used to measure the thickness of the thermal-sprayed coatings (Ref 46). For example, Floristan et al. (Ref 72) studied the thickness and porosity of plasma-sprayed $\mathrm{TiO}_{2}$ coatings by conducting digital image analysis on images taken by SEM.

\subsection{Application-Based Techniques}

In order to assess the functional characteristics of the thermal-sprayed metal coatings, the use of methodologies that are focused on specific responses of the coating-substrate material system is required. This section describes some evaluation techniques that have been developed for specific applications of thermal-sprayed coatings deposited onto polymer-based substrates.

7.2.1 Thermal Shock Resistance. Thermal shock is the sudden change in temperature that can cause the failure of a component due to stresses induced by high-temperature gradients. The resistance of materials to a sudden change in temperature without presenting failure is called thermal shock resistance, and assessing this property in multi-layer coated-polymers is of interest. As presented in Table 1, Huang et al. (Ref 22, 64) studied the feasibility of APS deposition of cobalt-nickel-chromium-aluminum-yttrium (CoNiCrAlY), Al, and Zn bond layers and a ceramic YSZ top layer to serve as a protective coating system on polyimide matrix composites. The thermal shock resistance of the a-sprayed specimens was evaluated by thermal shock testing, in which the samples were exposed to abrupt changes in temperature. The coated samples were heated to $400{ }^{\circ} \mathrm{C}$ in a furnace. Thereafter, the samples were quenched in water at room temperature, producing a high-temperature gradient in the coated samples. Cracks and delamination due to the abrupt change in temperature were examined under a SEM. The use of thermal shock resistance tests in this study allowed concluding that the $\mathrm{Zn}$ bond-coat exhibited higher thermal shock resistance than the $\mathrm{Al}$ and CoNiCrAlY bond-coats.

7.2.2 Fouling Resistance. Biofouling comprises the accumulation of organic materials on a surface, which has been shown to decrease the lifetime of marine structures (Ref $23,45,115,116)$. The design of techniques to avoid biofouling has been the main interest of several research studies (Ref 23, 45). Vucko et al. (Ref 23) used the cold spray process to embed copper-based particles onto HDPE and nylon composites. The suitability of copperembedded composites as a marine antifouling system was evaluated for 250 days. As-sprayed and unsprayed $140 \mathrm{~mm}$ x $170 \mathrm{~mm}$ samples were placed $200 \mathrm{~mm}$ below the water surface of the Townsville Yacht Club Lake (Queensland, Australia) in mid-December (Summer) and photographs were taken each week to track fouling development. This study showed that copper-embedded HDPE plates have similar antifouling properties to pure $\mathrm{Cu}$ plates after 250 days underwater. The coatings limited soft fouling formation (algae) and deterred the deposition of hard fouling (carbonate sediments), which, from a financial perspective, is the most detrimental to marine and water-based enterprises.

\section{Potential Applications}

\subsection{Electrically Conductive Structures}

The fabrication of electrically conductive thermalsprayed metal coatings onto polymers has gained attention as a fabrication technique for electrical sensors (Ref 30, 53, 117-119). However, the development of suitable thermal-sprayed electrically conductive coatings for engineering applications is currently an area of research (Ref 120). Several fundamental studies (Ref 17, 53, 121-123) have shown that the porous structure of metal thermalsprayed coatings results in electrical properties that differ from that of the bulk metal. Even though Ohmic resistive behavior can be observed in thermal-sprayed metal coatings, such as Ni-Al (Ref 124) and Al-12Si (Ref 118), the porosity and morphology of the coating strongly affect the ability of thermal-sprayed metal coatings to conduct electrical charges. For instance, Sampath et al. (Ref 121) reported that dense cold-sprayed $\mathrm{Cu}$ coatings can exhibit a $25 \%$ increase in electrical resistivity with respect to that of the bulk $\mathrm{Cu}$, while the resistivity of porous plasma-sprayed $\mathrm{Cu}$ coatings can increase by $300-400 \%$. Therefore, the development of thermal-sprayed metal coatings that are tailored to has electrical performance that approach those of the bulk metal requires precise control of the process parameters and knowledge of the cross-property relationships, such as porosity and electrical resistivity. Also, pores and oxide lamellas strongly affect the electrical behavior of thermal-sprayed metal coatings, leading to microscopic anisotropy. In contrast, the electrical resistivity of thin metallic coatings fabricated using vapor deposition methods, such as CVD and PECVD, exhibit a relatively homogeneous behavior due to the low level of microscopic defects (i.e., material grain boundaries) and higher uniformity and density of the deposits (Ref 38).

As shown in Table 3, limited studies exist on the electrical characterization of thermally sprayed metal coatings deposited onto polymer-based structures for electrical applications. Voyer et al. (Ref 34, 40) studied the deposition of electrically conductive $\mathrm{Al}$ coatings onto polyester fabrics deposited via the flame spraying process. Optimal flame spray deposition resulted in coatings that were 75$100 \mu \mathrm{m}$ thick with a sheet resistivity of at least $0.002 \Omega \mathrm{m} /$ $\mathrm{m}$ (Table 3 ). It was found that an electrically conductive Al coating can be fabricated without compromising the flexibility of the polyester fabric. Huonnic et al. (Ref 17) deposited flame-sprayed Al coatings onto cured glass and basalt FRPC tubes and measured the electrical resistance and resistivity of the metal layer to characterize the quality of the deposits. A minimum of two flame spray torch passes was required to produce a uniform and electrically continuous metal layer on the polymer-based tubes. No evidence of phase changes or oxidation was observed in the flame-sprayed coatings. However, the values of electrical resistivity of the porous $\mathrm{Al}$ coating were measured to be $6 \times 10^{-7}$ and $8 \times 10^{-7} \Omega \mathrm{m}$ (Table 3), which are one order of magnitude greater than the resistivity of annealed $\mathrm{Al}$ alloys $\left(3 \times 10^{-8} \Omega \mathrm{m}\right)$. Affi et al. (Ref 48) compared the electrical resistivity of 
cold- and plasma-sprayed Al coatings deposited onto carbon fiber-reinforced epoxy (thermoset) substrates. It was noted that the plasma-sprayed $\mathrm{Al}$ deposits exhibited higher resistivity values compared to those of cold-sprayed Al coatings, which may be a consequence of increased oxidation of sprayed particles at higher carrier gas temperatures. In another study, Gonzalez et al. (Ref 118) studied the electrical behavior of porous $(12-17 \%$ volumetric porosity) flame-sprayed Al-12Si coatings for damage detection in cross-ply FRPC substrates, as shown in Table 3. The change in the electrical resistance of the $\mathrm{Al}-12 \mathrm{Si}$ coating was measured during the application of a linear tensile load to the coated FRPC specimens. It was found that the change in resistance across the $\mathrm{Al}-12 \mathrm{Si}$ coating due to early matrix damage in the cross-ply FRPC was limited, but increased significantly as a result of fiberdominated failure and delamination in the substrate.

\subsection{Thermal Systems}

Typical thermal properties of the polymer-based materials do not allow for quick heat conduction through the material. Thermal-sprayed metal coatings can be used to improve the conduction of heat in polymer-based material structures. For instance, Therrien et al. (Ref 19) utilized flame-sprayed Al-12Si coatings on glass FRPC parts to study the heat conduction efficiency along the surface area of as-sprayed polymer-based plates. Al-12Sicoated samples were heated up with a resistance heating wire while thermocouples were used to measure the temperature distribution on the coated and bare sides of the polymer. As presented in Table 3, this study found that the high thermal conductivity of the flame-sprayed $\mathrm{Al}-12 \mathrm{Si}$ coating, at approximately $250 \mathrm{~W} / \mathrm{m} \mathrm{K}$, allows a more efficient conduction of heat to the surface of the FRPC substrate.

Additionally, methods that protect polymers from the adverse effects of high temperature are also required in the aerospace industry. Huang et al. (Ref 22) fabricated a multi-layer Al-YSZ thermal barrier coating onto quartz FRPC using APS. An Al bond layer and YSZ top layer were successfully deposited onto the polymer composite and the thermal shock resistance of the coating was evaluated. It was found that thermal spray deposition of an $\mathrm{Al}$ bond-coat with an YSZ top layer can serve as a thermal barrier to protect the polymer-based structure.

Prevention of ice accretion on the surface of polymerbased structures is another potential application of the metal coatings that are thermally sprayed onto polymer substrates. Ice accretion is the formation and accumulation of ice due to exposure to a super-cooled fluid. Rooks (Ref 15) proposed the use of plasma spraying in the fabrication of resistive heater elements for ice protection of the leading edge portion of the main rotor blade of a military helicopter. Lopera-Valle and McDonald (Ref 66, 67) investigated the possible application of flame-sprayed nickel-chromiumaluminum-yttrium (NiCrAlY) and $\mathrm{Ni}-20 \mathrm{Cr}$ coatings deposited onto FRPC parts for de-icing applications. As shown in Table 3, the coatings electrical resistance of the $\mathrm{NiCrAlY}$ and $\mathrm{Ni}-20 \mathrm{Cr}$ coatings was estimated between 3.2 and 3.55 $\Omega$. Electrical current was applied to coated samples to increase the surface temperature by resistive (Joule) heating. The surface temperature profiles of the coatings were measured under free and forced convection conditions at different ambient temperatures, ranging from -25 to $23{ }^{\circ} \mathrm{C}$. It was found that at ambient air temperatures below $0{ }^{\circ} \mathrm{C}$, the surface temperature of the coating, and in some cases, that of the FRPC remained above $0{ }^{\circ} \mathrm{C}$ for both the forced and free convection conditions. In addition, there was a nearly homogeneous temperature distribution over the coating surface. This suggested that flame-sprayed coatings may be used as heating elements to mitigate ice accretion on polymer-based structures, without the presence of areas of localized high temperatures (Ref 66, 67). In a subsequent study, Lopera-Valle and McDonald (Ref 125) evaluated the performance of NiCrAlY flame-sprayed coatings that were deposited onto FRPC substrates as deicing elements. The coated FRPC samples were placed inside a cold room at temperatures between -5 and $-25^{\circ} \mathrm{C}$, and water was sprayed over the specimens, simulating light to moderate rain, and leading to the formation of an ice layer of up to $4.5 \mathrm{~mm}$ thick. As in previous studies (Ref 66, 67), electrical current was applied to the coated samples, which generated an increase in the temperature of the ice-covered sample, and melted the ice layer by way of Joule heating. This study showed that the heat generated by the NiCrAlY flame-sprayed coatings successfully melted the ice, providing evidence of the feasibility of implementing flame-sprayed coatings on FRPC as embedded deicing elements (Ref 125). An existing implementation of this concept is the de-icing system integrated into the Boeing 787 Dreamliner CFRP composite wing that is based on a proprietary thermal spray deposition technique developed by GKN Aerospace (Redditch, UK) (Ref 35). This application comprises thermal-sprayed metal coatings deposited onto a fiber-reinforced polymer ply to create a resistive heater mat, which is embedded into the aircraft wings. However, the scientific literature available on thermal spray metallization of FRPC structures for aerospace applications is scarce, as indicated in Table 3. To date, only a preliminary preview by Bheekhun et al. (Ref 126) has been presented on the thermal spray metallization of PMC substrates in relation to gas turbine engine applications.

\section{Conclusion and Suggestions for Future Work}

Polymer-based materials can have excellent mechanical and physical properties, such as enhanced resistance to corrosion, resistance to wear, and high strength-to-weight ratio. However, the low thermal and electrical conductivities of polymer-based materials limit their use in electrical charge conduction applications and elevated temperature environments. Metallization of polymerbased materials by the deposition of metals is a possible means to augment their effective thermal and electrical conductivities. Also, the deposited metal coatings can 
provide new functionality for the new metal-polymer system such as resistive (Joule) heating applications.

In this study, research contributions on the thermal spray metallization of polymer-based materials were presented. One of the main challenges with thermal spraying on polymer materials is the inability to control the substrate temperature during the deposition process since most polymers have low thermal conductivity and heat capacity and may degrade or experience significant changes in properties at high temperatures. The review of different thermal spray deposition processes demonstrated that cold spraying, flame spraying, electric arc wire spraying, and plasma spraying have been employed in previous studies for the metallization of polymer materials. Although these processes can expose the polymer substrates to high heat loads, which depends on the spraying parameters and feedstock material, successful metal deposition onto polymer materials can be achieved. The use of compressed air cooling and deposition of low melting temperature metals as bond-coat prior to deposition of the final top coating were introduced as two methods to control the thermal load on the polymer-based substrate from the spray torch.

Knowledge of the temperature distribution within the substrate during the spray process can facilitate the sensitivity analysis to spray parameter changes and prevent thermal overload within the polymer substrate. Analytical models and numerical techniques have been used to model the thermal spraying process in an effort to predict the temperature distribution within the substrate during the spraying process. Substrate temperature distribution models that have good agreement with experiments were introduced. On the other hand, the number of studies focused on the temperature distribution within the polymer-based materials is limited and future work is needed in this area.

Pre-treatment of the polymer surface prior to thermal spraying was discussed and the previous research in this area was reviewed. Based on previous studies, grit blasting of polymer materials may not be the optimal pre-treatment option for thermal spray metallization due to the risk of inducing structural damage in the polymers. Roughening of the substrate by the inclusion of powder materials on the surface of the polymer substrates, either during the curing process or by an adhesive agent, was recommended. The protection provided to the polymerbased substrate by the low thermal conductivity roughening agent from the heat load during thermal spray metallization was briefly discussed. However, fundamental study and analysis in this area are needed and future research is required.

The review of the methods for evaluation and characterization of thermal-sprayed metal coatings deposited onto polymer substrates showed that most of the methods such as measurement of hardness, bond strength, chemical composition, and digital image analysis are similar to those used in respect of non-polymer substrates. However, novel techniques based on the final application of the polymer-metal system have been employed.
Improvement of thermal and electrical conductivities of the polymers has been the focus for deposition of the metal coating onto polymer-based substrates in most studies. On the other hand, it has been shown that the combination of the metal coating and the polymer can produce a material system that is capable of being employed in novel applications. The applications discussed in published studies included the use of the deposited coating as a heating element for de-icing purposes, antifouling, and structural damage detection. Overall, future work is needed in these areas to establish and test the possible novel applications of metal deposits onto polymer-based substrates. Some application-relevant areas that can be considered for future work and study are given below:

(1) The use of metal coatings as heating elements on coated FRPC pipes to decrease the viscosity of flowing fluids and minimize pump power requirements during low ambient temperature events;

(2) The use of metal coatings as heat tracers to improve the wear performance of coated protective elastomer liners;

(3) Structural health monitoring of polymer-based structures by controlling the impedance of the metal coating deposited on the outer surface of the structure or embedded in a laminated architecture; and

(4) The investigation of the temperature distribution in substrates exhibiting anisotropic thermal properties (e.g., fiber-reinforced polymers) during the thermal spray process, and development of analytical/numerical models that can account for substrate anisotropy.

\section{References}

1. P. Fauchais and A. Vardelle, Heat, Mass and Momentum Transfer in Coating Formation by Plasma Spraying, Int. J. Therm. Sci., 2000, 39(9-11), p 852-870

2. P. Fauchais and G. Montavon, Thermal and Cold Spray: Recent Developments, Key. Eng. Mater., 2008, 384, p 1-59

3. R.W. Smith and R. Knight, Thermal Spraying I: Powder Consolidation-from Coating to Forming, J. Minerals Metals Mater. Soc., 1995, 47(8), p 32-39

4. J.R. Davis, Handbook of Thermal Spray Technology, ASM International, Materials Park, OH, 2004, p 1-36

5. A. McDonald, M. Lamontagne, C. Moreau, and S. Chandra, Impact of Plasma-Sprayed Metal Particles on Hot and Cold Glass Surfaces, Thin Solid Films, 2006, 514(1-2), p 212-222

6. M.P. Dewar, A.G. McDonald, and A.P. Gerlich, Interfacial Heating During Low-Pressure Cold-Gas Dynamic Spraying of Aluminum Coatings, J. Mater. Sci., 2012, 47(1), p 184-198

7. T. Schmidt, F. Gartner, H. Assadi, and H. Kreye, Development of a Generalized Parameter Window for Cold Spray Deposition, Acta Mater., 2006, 54(3), p 729-742

8. P. Fauchais, M. Fukumoto, A. Vardelle, and M. Vardelle, Knowledge Concerning Splat Formation: An Invited Review, J. Therm. Spray Technol., 2004, 13(3), p 337-360

9. A. Moridi, S. Hassani-Gangaraj, M. Guagliano, and M. Dao, Cold Spray Coating: Review of Material Systems and Future Perspectives, Surf. Eng., 2014, 30(6), p 369-395

10. T. Goyal, R.S. Walia, T.S. Sidhu, and S. Samir, A Review of Coating Technology Processes and Recent Advancements, $\mathrm{Na}$ tional Conference on Advances in Manufacturing Technology 2012, Chandigarh, 2012, pp. II-1-II-5. 
11. D.S. Therrien, A.G. McDonald, and P. Mertiny, Temperature Measurements of Polymer Composite Flat Plates Coated with Aluminum-12silicon, International Thermal Spray Conference 2012 (Houston, TX), 2012, pp. 1-6

12. F.N. Longo, Industrial Guide-Markets, Materials, and Applications for Thermal-Sprayed Coatings, J. Therm. Spray Technol. 1992, 1(2), p 143-145

13. M. Vijay, V. Selvarajan, S. Yugeswaran, P.V. Ananthapadmanabhan, and K.P. Sreekumar, Effect of Spraying Parameters on Deposition Efficiency and Wear Behavior of Plasma Sprayed Alumina-Titania Composite Coatings, Plasma Sci. Technol., 2009, 11(6), p 666-673

14. O. Stier, Fundamental Cost Analysis of Cold Spray, 2013 International Thermal Spray Conference, Busan, 2014, pp. 131-139

15. B. Rooks, Robot Spraying of Helicopter Rotor Blade Ice Protection System, Ind. Robot, 2001, 28(4), p 313-315

16. F. Robitaille, M. Yandouzi, S. Hind, and B. Jodoin, Metallic Coating of Aerospace Carbon/Epoxy Composites by the Pulsed Gas Dynamic Spraying Process, Surf. Coat. Technol., 2009, 203(19), p 2954-2960

17. N. Huonnic, M. Abdelghani, P. Mertiny, and A. McDonald, Deposition and Characterization of Flame-Sprayed Aluminum on Cured Glass and Basalt Fiber-Reinforced Epoxy Tubes, Surf. Coat. Technol., 2010, 205(3), p 867-873

18. R. Gonzalez, A. McDonald, and P. Mertiny, Effect of FlameSprayed Al-12Si Coatings on the Failure Behaviour of Pressurized Fibre-Reinforced Composite Tubes, Polym. Test., 2013, 32(8), p 1522-1528

19. D.S. Therrien, Heat Transfer Analysis of Flame-sprayed Metalpolymer Composite Structures, University of Alberta, 2013. Dissertation

20. H. Ashrafizadeh, P. Mertiny, and A. McDonald, Determination of Temperature Distribution Within Polyurethane Substrates During Deposition of Flame-Sprayed Aluminum-12silicon Coatings Using Green's Function Modeling and Experiments, Surf. Coat. Technol., 2014, 259, p 625-636

21. X.L. Zhou, A.F. Chen, J.C. Liu, X.K. Wu, and J.S. Zhang, Preparation of Metallic Coatings on Polymer Matrix Composites by Cold Spray, Surf. Coat. Technol., 2011, 206(1), p 132-136

22. W. Huang, X. Fan, Y. Zhao, X. Zhou, X. Meng, Y. Wang, B. Zou, X. Cao, and Z. Wang, Fabrication of Thermal Barrier Coatings onto Polyimide Matrix Composites Via Air Plasma Spray Process, Surf. Coat. Technol., 2012, 207, p 421-429

23. M.J. Vucko, P.C. King, A.J. Poole, C. Carl, M.Z. Jahedi, and R. de Nys, Cold Spray Metal Embedment: An Innovative Antifouling Technology, Biofouling, 2012, 28(3), p 239-248

24. D. Giraud, F. Borit, V. Guipont, M. Jeandin, and J.M. Malhaire, Metallization of a polymer Using Cold Spray: Application to Aluminum Coating of Polyamide 66, International Thermal Spray Conference 2012 (Houston, TX), 2012, pp. 265-270.

25. A. Ganesan, J. Affi, M. Yamada, and M. Fukumoto, Bonding Behavior Studies of Cold Sprayed Copper Coating on the PVC Polymer Substrate, Surf. Coat. Technol., 2012, 207, p 262-269

26. M. Gardon, A. Latorre, M. Torrell, S. Dosta, J. Fernandez, and J.M. Guilemany, Cold Gas Spray Titanium Coatings onto a Biocompatible Polymer, Mater. Lett., 2013, 106, p 97-99

27. H. Ye and J. Wang, Preparation of Aluminum Coating on Lexan by Cold Spray, Mater. Lett., 2014, 137, p 21-24

28. H. Ashrafizadeh, P. Mertiny, A. McDonald, Evaluation of the Influence of Flame Spraying Parameters on Microstructure and Electrical Conductivity of Al-12Si Coatings Deposited on Polyurethane Substrates, International Thermal Spray Conference 2015 (Long Beach, CA), 2015, pp. 370-376.

29. S. Kuroda, J. Kawakita, M. Watanabe, and H. Katanoda, Warm Spraying-A Novel Coating Process Based on High-Velocity Impact of Solid Particles, Sci. Technol. Adv. Mater., 2008, 9(3), p 1-17

30. S. Sampath, Opportunities for Thermal Spray in Functional Materials, Electronics, and Sensors, Adv. Mater. Process., 2013, 171(11), p 69-70

31. P. Mertiny, K. Juss, and Bell, Corrosion and Erosion Resistant Polymer Composite Pipe for Oil Sands Hydrotransport, NACEInternational Corrosion Conference Series (New Orleans, LO), 2008, pp. 086671-086678.
32. J.H. Koo, B. Muskopf, G. McCord, P. Van Dine, B. Spencer, U. Sorathia, and S. Venumbaka, Characterization of Fire Safe Polymer Matrix Composites For Naval Applications, in International SAMPE Symposium and Exhibition (San Marcos, TX), 2001, pp. 2170-2182.

33. R.N. Walters, Fire-Safe Polymer Composites, International SAMPE Symposium and Exhibition (Long Beach, CA), 2002, pp. $716-727$

34. J. Voyer, P. Schulz, and M. Schreiber, Conducting FlameSprayed Al Coatings on Textile Fabrics, J. Therm. Spray Technol., 2008, 17(4), p 583-588

35. J. Sloan, 787 Integrates New Composite Wing Deicing System, January ed. High Performance Composites, p. 27, Gardner Business Media, 2009

36. T.G. McNaughton and K.W. Horch, Metallized Polymer Fibers as Leadwires and Intrafascicular Microelectrodes, J. Neurosci. Methods, 1996, 70(1), p 103-110

37. J. Siegel and V. Kotal, Preparation of Thin Metal Layers on Polymers, Acta Polytech., 2007, 47(1), p 9-11

38. T. Duguet, F. Senocq, L. Laffont, and C. Vahlas, Metallization of Polymer Composites by Metalorganic Chemical Vapor Deposition of $\mathrm{Cu}$ : Surface Functionalization Driven Films Characteristics, Surf. Coat. Technol., 2013, 230, p 254-259

39. K.P. Gritsenko, Metal-polymer Optical Storage Media Produced by PECVD, Thin Solid Films, 1993, 227(1), p 1-2

40. J. Voyer, P. Schulz, and Schreiber, Electrically Conductive Flame Sprayed Aluminum Coatings on Textile Substrates, International Thermal Spray Conference 2008, (Maastricht, Limburg), 2008, pp. 818-823.

41. L. Pawlowski, The Science and Engineering of Thermal Spray Coatings, 2nd ed., Wiley, New York, 2008

42. C. Katsoulis, B.K. Kandola, P. Myler, and E. Kandare, Post-fire Flexural Performance of Epoxy-Nanocomposite Matrix Glass Fibre Composites Containing Conventional Flame Retardants, Composites Part A, 2012, 43(8), p 1389-1399

43. An Introduction to Thermal Spray. Oerlikon Metco. http:// www.oerlikon.com/ecomaXL/files/metco/oerlikon_Thermal Spray_Brochure_EN5.pdf. 2014. Last accessed: Jun 1, 2015.

44. P.C. King, A.J. Poole, S. Horne, R. de Nys, S. Gulizia, and M.Z. Jahedi, Embedment of Copper Particles into Polymers by Cold Spray, Surf. Coat. Technol., 2013, 216, p 60-67

45. M.J. Vucko, P.C. King, A.J. Poole, M.Z. Jahedi, and R. de Nys, Polyurethane Seismic Streamer Skins: An Application of Cold Spray Metal Embedment, Biofouling, 2013, 29(1), p 1-9

46. A.S.M. Ang and C.C. Berndt, A Review of Testing Methods for Thermal Spray Coatings, Int. Mater. Rev., 2014, 59(4), p 179-223

47. R. Lupoi and W. O'Neill, Deposition of Metallic Coatings on Polymer Surfaces Using Cold Spray, Surf. Coat. Technol., 2010, 205(7), p 2167-2173

48. J. Affi, H. Okazaki, M. Yamada, and M. Fukumoto, Fabrication of Aluminum Coating onto CFRP Substrate by Cold Spray, Mater. Trans., 2011, 52(9), p 1759-1763

49. A. Sturgeon, B. Dunn, S. Celotto, and B. O'Neill, Cold Sprayed Coatings for Polymer Composite Substrates, 10th International Symposium on Materials in a Space Environment and The 8th International Conference on Protection of Materials and Structures in a Space Environment (Collioure, Languedoc-Roussillon), 2006, pp. 616-1-616-6.

50. M. Fukumoto, H. Terada, M. Mashiko, K. Sato, M. Yamada, and E. Yamaguchi, Deposition of Copper Fine Particle by Cold Spray Process, Mater. Transactions, 2009, 50(6), p 14821488

51. B. Jodoin, P. Richer, G. Berube, L. Ajdelsztajn, A. Erdi-Betchi, and M. Yandouzi, Pulsed-Gas Dynamic Spraying: Process Analysis, Development and Selected Coating Examples, Surf. Coat. Technol., 2007, 201(16-17), p 7544-7551

52. G.M. Nelson, J.A. Nychka, and A.G. McDonald, Structure, Phases, and Mechanical Response of Ti-Alloy Bioactive Glass Composite Coatings, Mater. Sci. Eng. C, 2014, 36(1), p 261-276

53. H. Boyer, A. McDonald, and P. Mertiny, Flame Spray Deposition of Electrically Conductive Traces on Polymer Substrates for System Integrated Composite Structures, in: Composites 2012 (Las Vegas, NV), 2012, pp. 1-6. 
54. M.H.A. Malek, N.H. Saad, S.K. Abas, and N.M. Shah, Thermal Arc Spray Overview, in: 2013 International Conference on Manufacturing, Optimization, Industrial and Material Engineering (Bandung, West Java), 2013, pp. 012028-1-012028-11.

55. X. Wang, J. Heberlein, E. Pfender, and W. Gerberich, Effect of Nozzle Configuration, Gas Pressure, and Gas Type On Coating Properties in Wire Arc Spray, J. Therm. Spray Technol., 1999, 8(4), p 565-575

56. A. Liu, M. Guo, M. Zhao, H. Ma, and S. Hu, Arc Sprayed ErosionResistant Coating for Carbon Fiber Reinforced Polymer Matrix Composite Substrates, Surf. Coat. Technol., 2006, 200(9), p 3073-3077

57. A. Liu, M. Guo, J. Gao, and M. Zhao, Influence of Bond Coat on Shear Adhesion Strength of Erosion and Thermal Resistant Coating for Carbon Fiber Reinforced Thermosetting Polyimide, Surf. Coat. Technol., 2006, 201(6), p 2696-2700

58. E. Lugscheider and T. Weber, Plasma Spraying-An Innovative Coating Technique: Process Variants and Applications, IEEE Trans. Plasma Sci., 1990, 18(6), p 968-973

59. A. Ganesan, M. Yamada, and M. Fukumoto, The Effect of CFRP Surface Treatment on the Splat Morphology and Coating Adhesion Strength, in: International Thermal Spray Conference 2013 (Busan, Yeongnam), 2014, pp. 236-244

60. R. Beydon, G. Bernhart, and Y. Segui, Measurement of Metallic Coatings Adhesion to Fibre Reinforced Plastic Materials, Surf. Coat. Technol., 2000, 126(1), p 39-47

61. S. Guanhong, H. Xiaodong, J. Jiuxing, and S. Yue, Parametric Study of $\mathrm{Al}$ and $\mathrm{Al}_{2} \mathrm{O}_{3}$ Ceramic Coatings Deposited by Air Plasma Spray Onto Polymer Substrate, Appl. Surf. Sci., 2011, 257(17), p 7864-7870

62. G. Sun, X. He, J. Jiang, Y. Sun, and Y. Zhong, A Study on the Deposition of $\mathrm{Al}_{2} \mathrm{O}_{3}$ Coatings on Polymer Substrates by a Plasma Spray/Micro-Arc Oxidation Two-Step Method, $J$. Therm. Spray Technol., 2013, 22(1), p 27-35

63. M. Mellali, P. Fauchais, and A. Grimaud, Influence of Substrate Roughness and Temperature on the Adhesion/Cohesion of Alumina Coatings, Surf. Coat. Technol., 1996, 81(2-3), p 275-286

64. W. Huang, Y. Zhao, X. Fan, X. Meng, Y. Wang, X. Cai, X. Cao, and Z. Wang, Effect of Bond Coats on Thermal Shock Resistance of Thermal Barrier Coatings Deposited onto Polymer Matrix Composites Via Air Plasma Spray Process, J. Therm. Spray Technol., 2013, 22(6), p 918-925

65. H. Ashrafizadeh, A. McDonald, and P. Mertiny, Deposition of Electrically Conductive Coatings on Castable Polyurethane Elastomers by the Flame Spraying Process, J. Therm. Spray Technol., 2016, 25(3), p 419-430

66. A. Lopera-Valle, A. McDonald, Use of Flame-Sprayed Coatings as Heating Elements for Polymer-Based Composite Structures, in: International Thermal Spray Conference 2015 (Long Beach, CA), 2015, pp. 1183-1190

67. A. Lopera-Valle and A. McDonald, Application of Flame-Sprayed Coatings as Heating Elements for Polymer-Based Composite Structures, J. Therm. Spray Technol., 2015, 24(7), p 1289-1301

68. A. Ganesan, M. Yamada, and M. Fukumoto, Cold Spray Coating Deposition Mechanism on the Thermoplastic and Thermosetting Polymer Substrates, J. Therm. Spray Technol., 2013, 22(8), p 1275-1282

69. C. Beyler and M. Hirschler, SFPE Handbook of Fire Protection Engineering, 3rd ed, National Fire Protection Association (Quincy, MA), 2001, pp. 1-110-1-131.

70. P.S. Ghoshdastidar, Heat Transfer, 2nd ed., Oxford University Press, New Delhi, India, 2012, p 529-577

71. L. PawŁowski, Temperature Distribution in Plasma-Sprayed Coatings, Thin Solid Films, 1981, 81(1), p 79-88

72. M. Floristan, R. Fontarnau, A. Killinger, and R. Gadow, Development of Electrically Conductive Plasma Sprayed Coatings on Glass Ceramic Substrates, Surf. Coat. Technol., 2010, 205(4), p 1021-1028

73. F. Hugot, J. Patru, P. Fauchais, and L. Bianchi, Modeling of a Substrate Thermomechanical Behavior During Plasma Spraying, J. Mater. Process. Technol., 2007, 190(1-3), p 317-323

74. Y. Chen, X. Liang, Y. Liu, J. Bai, and B. Xu, Finite Element Modeling of Coating Formation and Transient Heat Transfer in the Electric Arc Spray Process, Int. J. Heat Mass Transfer, 2010, 53(9-10), p 2012-2021

75. Y. Zhu, H. Liao, and C. Coddet, Transient Thermal Analysis and Coating Formation Simulation of Thermal Spray Process by Finite Difference Method, Surf. Coat. Technol., 2006, 200(1617), p 4665-4673

76. Y. Bao, T. Zhang, and D.T. Gawne, Non-steady State Heating of Substrate and Coating During Thermal-Spray Deposition, Surf. Coat. Technol., 2005, 194(1), p 82-90

77. T. Zhang, Y. Bao, D.T. Gawne, and P. Mason, Effect of a Moving Flame on the Temperature of Polymer Coatings and Substrates, Prog. Org. Coat., 2011, 70(1), p 45-51

78. S.C. Wu, H.O. Zhang, Q. Tang, L. Chen, and G.L. Wang, Meshless Analysis of the Substrate Temperature in Plasma Spraying Process, Int. J. Therm. Sci., 2009, 48(4), p 674-681

79. H. Ashrafizadeh, P. Mertiny, and A. McDonald, Analytical and Numerical Determination of Transient Temperature Within a Polyurethane Substrate During a Flame Spraying Process, in: The Canadian Society for Mechanical Engineering International Congress, Toronto, ON, 2014, pp. 1-6.

80. Y. Zhao, Z. Wu, and S. Bai, Study on Thermal Properties of Graphene Foam/Graphene Sheets Filled Polymer Composites, Composites Part A, 2015, 72, p 200-206

81. S.M. Lebedev and O.S. Gefle, Evaluation of Electric, Morphological and Thermal Properties of Thermally Conductive Polymer Composites, Appl. Therm. Eng., 2015, 91, p 875-882

82. W. Fan, J. Li, Y. Zheng, T. Liu, X. Tian, and R. Sun, Influence of Thermo-oxidative Aging on the Thermal Conductivity of Carbon Fiber Fabric Reinforced Epoxy Composites, Polym. Degrad. Stab., 2016, 123, p 162-169

83. Y.J. Noh and S.Y. Kim, Synergistic Improvement of Thermal Conductivity in Polymer Composites Filled with Pitch Based Carbon Fiber and Graphene Nanoplatelets, Polym. Test., 2015, 45, $\mathrm{p}$ 132-138

84. Y. Zhao, Y. Zhang, Z. Wu, and S. Bai, Synergic Enhancement of Thermal Properties of Polymer Composites by Graphene Foam and Carbon Black, Composites Part B, 2016, 84, p 52-58

85. ASTM E384-11e1, Standard Test Method for Knoop and Vickers Hardness of Materials, West Conshohocken, PA, ASTM International, 2011.

86. B.D. Cullity, Elements of X-ray Diffraction, 2nd ed., AddisonWesley, Reading, MA, 1978

87. S.M. Walley, Historical Origins of Indentation Hardness Testing, Mater. Sci. Technol., 2012, 28(9-10), p 1028-1044

88. L. Berger, Comprehensive Hard Materials, 1st ed., Elsevier, Oxford, 2014, p 471-506

89. P.L. Fauchais, J.V.R. Heberlein, and M. Boulos, Thermal Spray Fundamentals-From Powder to Part, 1st ed., Springer, New York, 2014, p 1113-1235

90. C.K. Lin and C.C. Berndt, Measurement and Analysis of Adhesion Strength for Thermally Sprayed Coatings, J. Therm. Spray Technol., 1994, 3(1), p 75-104

91. E. Lopez Cantera and B.G. Mellor, Fracture Toughness and Crack Morphologies in Eroded WC-Co-Cr Thermally Sprayed Coatings, Mater. Lett., 1998, 37(4-5), p 201-210

92. J.M. Antunes, A. Cavaleiro, L.F. Menezes, M.I. Simoes, and J.V. Fernandes, Ultra-microhardness Testing Procedure with Vickers Indenter, Surf. Coat. Technol., 2002, 149(1), p 27-35

93. ASTM C1326-13, Standard Test Method for Knoop Indentation Hardness of Advanced Ceramics, West Conshohocken, PA, ASTM International, 2013.

94. ASTM C1327-15, Standard Test Method for Vickers Indentation Hardness of Advanced Ceramics, West Conshohocken, PA, ASTM International, 2015.

95. D. Chicot, H. Ageorges, M. Voda, G. Louis, M.A. Ben Dhia, C.C. Palacio, and S. Kossman, Hardness of thermal sprayed coatings: Relevance of the scale of measurement, Surf. Coat. Technol., 2015, 268, p 173-179

96. G.K. Beshish, C.W. Florey, F.J. Worzala, and W.J. Lenling, Fracture Toughness of thermal Spray Ceramic Coatings Determined by The Indentation Technique, J. Therm. Spray Technol., 1993, 2(1), p 35-38 
97. M. Gell, J. Eric, V. Krishnakumar, K. McCarron, B. Barber, Y. Sohn, and V.K. Tolpygo, Bond Strength, Bond Stress and Spallation Mechanisms of Thermal Barrier Coatings, Surf. Coat. Technol., 1999, 120-121, p 53-60

98. C.C. Berndt, The Adhesion of Flame and Plasma Sprayed Coatings, Monash University, 1980. Dissertation.

99. A.A. Elmoursi and N. Patel, Adhesion Measurement Procedures for Kinetic and Thermal Spray Coatings Using a Stud-Pull Tester, J. Adhes. Sci. Technol., 2004, 18(5), p 597-606

100. M. Ivosevic, R. Knight, S.R. Kalidindi, G.R. Palmese, and J.K. Sutter, Adhesive/Cohesive Properties of Thermally Sprayed Functionally Graded Coatings for Polymer Matrix Composites, J. Therm. Spray Technol., 2005, 14(1), p 45-51

101. H. Assadi, F. Gärtner, T. Stoltenhoff, and H. Kreye, Bonding Mechanism in Cold Gas Spraying, Acta Mater., 2003, 51(15), p 4379-4394

102. ASTM D4541-09e1, Standard Test Method for Pull-Off Strength of Coatings Using Portable Adhesion Testers, West Conshohocken, PA, USA, ASTM International, 2009.

103. C.C. Berndt, Tensile Adhesion Testing Methodology for Thermally Sprayed Coatings, J. Mater. Eng., 1990, 12(2), p 151-158

104. S. Amada and T. Hirose, Influence of Grit Blasting Pre-treatment on the Adhesion Strength of Plasma Sprayed Coatings: Fractal Analysis of Roughness, Surf. Coat. Technol., 1998, 102(1-2), p 132-137

105. M. Sexsmith and T. Troczynski, Peel Adhesion Test for Thermal Spray Coatings, J. Therm. Spray Technol., 1994, 3(4), p 404-411

106. H. Kurzweg, R.B. Heimann, T. Troczynski, and M.L. Wayman, Development of Plasma-Sprayed Bioceramic Coatings with Bond Coats Based on Titania and Zirconia, Biomaterials, 1998, 19(16), p 1507-1511

107. C. Bolis, L. Berthe, M. Boustie, M. Arrigoni, S. Barradas, and M. Jeandin, Physical Approach to Adhesion Testing Using Laser-Driven Shock Waves, J. Phys. D, 2007, 40(10), p 3155-3163

108. S. Barradas, R. Molins, M. Jeandin, M. Arrigoni, M. Boustie, C. Bolis, L. Berthe, and M. Ducos, Application of Laser Shock Adhesion Testing to the Study of the Interlamellar Strength and Coating-Substrate Adhesion in Cold-Sprayed Copper Coating of Aluminum, Surf. Coat. Technol., 2005, 197(1), p 18-27

109. L. Berthe, M. Arrigoni, M. Boustie, J. Cuq-Lelandais, C. Broussillou, G. Fabre, M. Jeandin, V. Guipont, and M. Nivard, State-of-the-Art Laser Adhesion Test (LASAT), Nondestr. Test. Eval., 2011, 26(3-4), p 303-317

110. X. Chen, J. Yuan, J. Huang, K. Ren, Y. Liu, S. Lu, and H. Li, Large-Scale Fabrication of Superhydrophobic Polyurethane/ Nano- $\mathrm{Al}_{2} \mathrm{O}_{3}$ Coatings by Suspension Flame Spraying for Anticorrosion Applications, Appl. Surf. Sci., 2014, 311, p 864-869

111. J.D. Osorio, A. Lopera-Valle, A. Toro, and J.P. HernandezOrtiz, Phase Transformations in Air Plasma-Sprayed YttriaStabilized Zirconia Thermal Barrier Coatings, Dyna, 2014, 81(185), p 13-18

112. D. Brandon and W.D. Kaplan, Microstructural Characterization of Materials, 2nd ed., Wiley, New York, 2008
113. J. Ilavsky, C.C. Berndt, and J. Karthikeyan, Mercury Intrusion Porosimetry of Plasma-Sprayed Ceramic, J. Mater. Sci., 1997, 32(15), p 3925-3932

114. J. Matejicek, B. Kolman, J. Dubsky, K. Neufuss, N. Hopkins, and J. Zwick, Alternative Methods for Determination of Composition and Porosity in Abradable Materials, Mater. Charact., 2006, 57(1), p 17-29

115. M. Legg, M.K. Yücel, I. Garcia de Carellan, V. Kappatos, C. Selcuk, and T.H. Gan, Acoustic Methods for Biofouling Control: A Review, Ocean Eng., 2015, 103, p 237-247

116. D.M. Yebra, S. Kiil, and K. Dam-Johansen, Antifouling Technology-Past, Present and Future Steps Towards Efficient and Environmentally Friendly Antifouling Coatings, Prog. Org. Coat., 2004, 50(2), p 75-104

117. R. Gonzalez, A.G. McDonald, and P. Mertiny, Damage Detection Method for Fiber-Reinforced Polymer Composites Using Al-12Si Flame-Sprayed Coatings, in: SAMPE Seattle 2014 Conference, (Seattle, WA), 2014, pp. 4056-1-4056-11

118. R. Gonzalez, P. Mertiny, and A. McDonald, Damage Detection Framework for Fiber-Reinforced Polymer Composites Using Al-12Si Flame-Sprayed Coatings, in: Canadian International Conference on Composite Materials, (Edmonton, AB), 2015, pp. 1-8

119. M. Fasching, F.B. Prinz, and L.E. Weiss, 'Smart' Coatings: A Technical Note, J. Therm. Spray Technol., 1995, 4(2), p 133-136

120. M. Prudenziati and M.L. Gualtieri, Electrical Properties of Thermally Sprayed Ni- and Ni20Cr-Based Resistors, J. Therm. Spray Technol., 2008, 17(3), p 385-394

121. S. Sampath, H. Herman, A. Patel, R. Gambino, R. Greenlaw, and E. Tormey, Thermal Spray Techniques for Fabrication of Meso-electronics and Sensors, in: Materials Development for Direct Write Technologies, April 24, 2000-April 26, 2000, pp. $181-188$

122. A. Sharma, R.J. Gambino, and S. Sampath, Electrical Conduction in Thermally Sprayed Thin Metallic Coatings, in: 2005 Materials Research Society Fall Meeting, 2006, pp. 287-292.

123. N. Margadant, S. Siegmann, J. Patscheider, T. Keller, W. Wagner, J. Ilavsky, J. Pisacka, G. Barbezat, and P.S. Fiala, Microstructure-Property Relationships and Cross-PropertyCorrelations of Thermal Sprayed Ni-Alloy Coatings, in International Thermal Spray Conference 2001, Singapore, 2001, pp. 643-652.

124. A. Sharma, R.J. Gambino, and S. Sampath, Anisotropic Electrical Properties in Thermal Spray Metallic Coatings, Acta Mater., 2006, 54(1), p 59-65

125. A. Lopera-Valle and A. McDonald, Flame-Sprayed Coatings as De-icing Elements for Fiber-Reinforced Polymer Composite Structures: Modeling and Experimentation, Int. J. Heat Mass Transfer, 2016, 97, p 56-65

126. N. Bheekhun, A.R. Abu Talib, and M.R. Hassan, Thermal Spray Coatings for Polymer Matrix Composites in Gas Turbine Engines: A Literary Preview, Int. Rev. Aerosp. Eng., 2014, 7(3), p 84-87 